\title{
An analysis of variations in isentropic melt productivity
}

\author{
By P. D. Asimow ${ }^{1}$, M. M. Hirschmann ${ }^{1,2}$ And E. M. Stolper ${ }^{1}$ \\ ${ }^{1}$ Division of Geological and Planetary Sciences, California Institute of Technology, \\ Pasadena, CA 91125, USA \\ ${ }^{2}$ Department of Geology, University of North Carolina, \\ Chapel Hill, NC 27599, USA
}

The amount of melt generated per unit pressure drop during adiabatic upwelling, the isentropic melt productivity, cannot be determined directly from experiments and is commonly assumed to be constant or to decrease as melting progresses. From analysis of one- and two-component systems and from calculations based on a thermodynamic model of peridotite partial melting, we show that productivity for reversible adiabatic (i.e. isentropic) depressurization melting is never constant; rather, productivity tends to increase as melting proceeds. Even in a one-component system with a univariant solid-liquid boundary, the $1 / T$ dependence of $(\partial S / \partial T)_{P}$ and the downward curvature of the solidus (due to greater compressibility of liquids relative to minerals) lead to increased productivity with increasing melt fraction during batch fusion (and even for fractional fusion in some cases). Similarly, for multicomponent systems, downward curvature of contours of equal melt fraction between the solidus and the liquidus contributes to an increase in productivity as melting proceeds. In multicomponent systems, there is also a lever-rule relationship between productivity and the compositions of coexisting liquid and residue such that productivity is inversely related to the compositional distance between coexisting bulk solid and liquid. For most geologically relevant cases, this quantity decreases during progressive melting, again contributing to an increase in productivity with increasing melting. These results all suggest that the increases in productivity with increasing melt fraction (punctuated by drops in productivity upon exhaustion of each phase from the residue) predicted by thermodynamic modelling of melting of typical mantle peridotites using MELTS are neither artifacts nor unique properties of the model, but rather general consequences of adiabatic melting of upwelling mantle.

\section{Introduction}

The amount of melting experienced by upwelling mantle is one of the most important parameters required for understanding the dynamics of basalt production and the observed compositional variability of basalts at mid-ocean ridges and sites of hot spot magmatism. The key parameter is the 'productivity' of the melting process (i.e. the amount of melt production per decrement of pressure (Hirschmann et al. 1994)), which exerts important controls on the dynamics and style of melt extraction, particularly if it varies with depth (Spiegelman 1993; Asimow et al. 1995a). The productivity also relates the geometry of the melting region to the average depth of melt

Phil. Trans. R. Soc. Lond. A (1997) 355, 255-281

(C) 1997 The Royal Society

Printed in Great Britain

255

$\mathrm{T}_{\mathrm{E}} \mathrm{X}$ Paper 
generation and to the total amount of melt produced, and therefore to the thickness of the oceanic crust (Langmuir et al. 1992). The motivation for this paper is that the primary information available from the study of igneous rocks, their compositions and volumes, cannot be interpreted in terms of source dynamics and geometry without an understanding of the factors influencing productivity in upwelling mantle.

Mantle upwelling at mid-ocean ridges and plumes in the absence of melt or fluid flow is usually approximated as an adiabatic process. To the extent that upwelling is slow, relative to mass and thermal transfer in the ascending peridotite, the process can also be envisioned as reversible. Under these conditions, processes occurring in upwelling mantle can be approximated as isentropic (Verhoogen 1965; McKenzie 1984). Once melt or fluid migration is allowed to occur or the effects of viscous deformation of the solids are considered, the process is no longer locally adiabatic or isentropic, and indeed, no simple thermodynamic constraints can be applied to the general case. Nevertheless, certain idealized end-member processes, such as batch fusion or fractional fusion (in which each increment of melt production during upwelling can be approximated as adiabatic and reversible), can be evaluated relatively simply from a thermodynamic perspective. However, despite the apparent simplicity of the problem when posed thermodynamically - e.g. for the reversible adiabatic case, pressure $(P)$, entropy $(S)$ and chemical composition are the independent variables in upwelling mantle and the equilibrium state is one of minimum enthalpy $(H)$ - the general features of productivity during adiabatic depressurization of mantle peridotite (and even of simpler, model systems) are little understood. The difficulty is partly that adiabatic processes are not readily simulated by experiment; i.e. whereas it is relatively simple to do an experiment at fixed or known $P$, temperature $(T)$, and chemical composition, there is no straightforward way to do an experiment at fixed or known $S$ or $H$ at high pressure. Another difficulty, however, is that there is, to our knowledge, no general treatment of adiabatic melting and its consequences even in simple systems, so there is no framework or background for understanding the behaviour of complex natural systems undergoing this process. Although space limitations prevent us from presenting a complete treatment, the goal of this paper is to expose some of the key parameters entering into the process of isentropic melting of the mantle and, by illustrating some of the expected behaviours and what causes them, to help calibrate people's intuition about this important process.

\section{Background and previous work}

The simplest approach to estimating melt production in upwelling peridotite is to assume that melt fraction increases linearly as pressure decreases; i.e. isentropic productivity is assumed to be constant (Turcotte \& Ahern 1978; Klein \& Langmuir 1987; Niu \& Batiza 1991; Kinzler \& Grove 1992). In other cases, plausible assumptions have been made that lead to decreasing productivity with progressive decompression; for example, McKenzie \& Bickle (1988) inferred, based on available peridotite melting data, that melt production would be enhanced near the solidus of natural peridotite (similar to the behaviour of a simple system at a eutectic or peritectic; see McKenzie \& Bickle 1990), and Langmuir et al. (1992) argued that melting is more productive at high pressure because the solidus and liquidus are closer together. Although both of these effects could be important under some conditions, we show below that decreasing productivity during upwelling is exactly the opposite of what is expected in most natural cases; i.e. productivity is generally smaller at the

Phil. Trans. R. Soc. Lond. A (1997) 

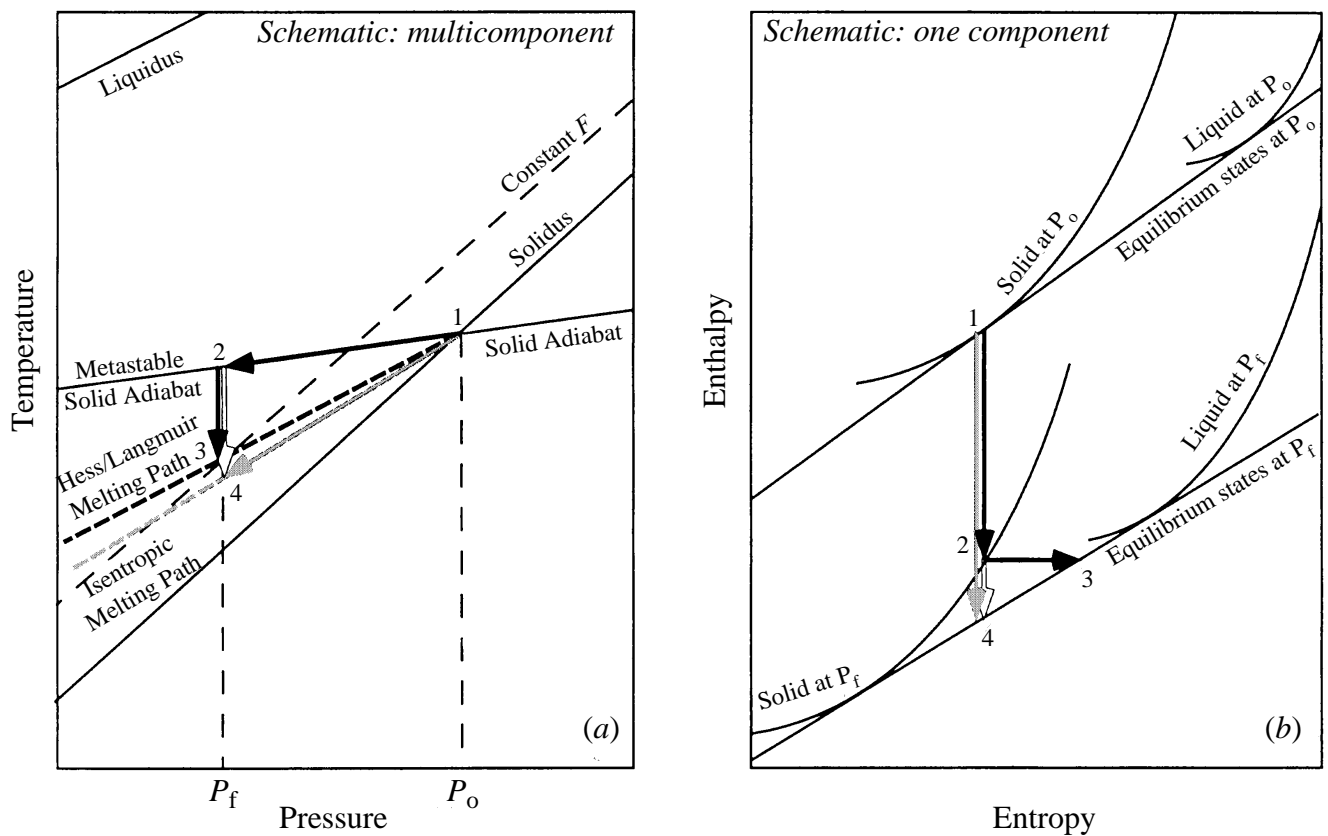

Figure 1. Schematic comparison of enthalpy- and entropy-conservation during adiabatic melting. (a) In $P-T$ space, a parcel of adiabatically upwelling mantle intersects its solidus at $P_{0}$, state 1. At lower pressure $P_{f}$, the metastable extension of the solid adiabat is state 2 . The stable partially molten state 3 is obtained by an adiabatic, isobaric (i.e. isenthalpic) process whereby the enthalpy recovered by cooling from state 2 to state 3 equals that required to melt up to some degree of melting $F$. State 4 is reached by reversible, adiabatic (i.e. isentropic) melting from state 1. (b) In $H-S$ space, the difference between the two adiabatic processes (the isentropic path from $1 \rightarrow 4$, shown as a gray arrow, versus the path from $1 \rightarrow 2 \rightarrow 3$, shown as black arrows) is shown for a hypothetical one-component system. The partially molten, stable state 4 is reached by adiabatic and reversible upwelling from the stable solid state 1 (on the solidus at $P_{0}$ ); the direct path from $1 \rightarrow 4$ is accomplished in a series of infinitesimal, reversible, adiabatic decompression steps; this state is clearly the minimum possible $H$ for this $S$ at $P_{f}$. State 2 is the metastable solid state at $P_{f}$ reached by reversible, adiabatic (i.e. constant $S$ ) decompression from state 1 at $P_{0}$. State 3 is shown to be the stable, partially molten state on the tie-line between solid and liquid at $P_{f}$ that has the same enthalpy as state 2 (reached by an irreversible, adiabatic, isobaric path at $P_{f}$ that maximizes $S$ ). Clearly, state 3 has higher $H$ and higher $S$ than state 4. Furthermore, application of the lever rule along the tie-line shows that state 3 has higher $F$ than state 4 . Returning to $(a)$, note that in a multicomponent system state 3 generally also has higher $T$ than state 4 , although in a one-component system both states lie on the solidus and are indistinguishable in $P-T$ space.

initiation of decompression melting and increases with progressive decompression. Note that in this paper we restrict our attention to changes in productivity with progressive melting along particular adiabats; we leave comparisons among adiabats of different potential temperature for future work.

A widely used approach to estimating adiabatic melting paths is based on the assumption that at a given pressure the enthalpy of the metastable solid adiabat (a state that can be readily calculated from an initially stable subsolidus assemblage) and that of the stable partially molten adiabat are equal (Ramberg 1972; Cawthorn 1975; Hess 1992; Langmuir et al. 1992; Longhi 1992; Hart 1993). In practice, these authors balanced the enthalpy required to melt the metastable solid against the enthalpy recovered by cooling to the stable partially molten assemblage. Although

Phil. Trans. R. Soc. Lond. A (1997) 
these authors presumably intended to calculate the amount of melt produced on reversible, adiabatic upwelling of peridotite, they actually calculated the amount of melt produced on a somewhat different adiabatic path. Consider figure 1, where this melting path (informally labelled the 'Hess-Langmuir melting path') is compared with isentropic upwelling in $P-T$ space (figure 1a) and in the less familiar but more informative $H-S$ plane (figure $1 b$ ). We have drawn figure $1 a$ for a multicomponent system, so that the melting paths do not coincide with the solidus, but for simplicity we have drawn figure $1 b$ for a one-component system. In $H-S$ space, the locus of states of a phase at constant pressure fall on a curve whose slope is temperature (i.e. $\left.(\partial H / \partial S)_{P}=T\right)$. The coexistence of two phases at equilibrium requires equal $T$ and equal $P$, so it is represented by a tie-line tangent to isobaric curves for the two phases. The isentropic path from stable state 1 on the solidus at $P_{0}$ to the stable, partially molten state 4 at $P_{f}$ is vertical in $H-S$ space. The Hess-Langmuir melting path, however, corresponds to a path on figure $1 b$ from the stable state 1 at $P_{0}$ to the metastable solid state 2 at $P_{f}$ (reached by a reversible adiabatic decompression), followed by a second path to the stable partially molten state 3 at $P_{f}$ (which has the same enthalpy as state 2 ). Figure $1 b$ shows that state 3 is at a higher melt fraction $(F)$, higher $S$ and higher $H$ than state 4 . For a multicomponent system, state 3 can also be at a higher $T$ than state 4 on the isentropic path. Hence the process that these authors actually approximated contains an irreversible, isobaric, adiabatic melting step (i.e. the adiabatic path from state 2 to state 3 at constant $P$ and $H$ leading to maximization of $S$ ), which leads to more melting than that produced by reversible adiabatic upwelling. Although the quantitative differences between these two paths are small, particularly at low degrees of melting, this example illustrates the importance of precise definition of the thermodynamics governing the melting process. Note that this treatment is not 'wrong' in that it does follow an adiabatic path, just not the reversible one, and it is possible that such a path could be of petrologic or geophysical interest; e.g. at a solid-solid phase transformation if the transition is kinetically inhibited (Solomatov \& Stevenson 1994).

An alternative to this approach would be to estimate melt production during reversible (i.e. isentropic) upwelling by balancing $S$ rather than $H$ in equivalent calculations comparing the metastable solid assemblage and the stable partially molten assemblage (i.e. by breaking the isentropic path from state 1 to state 4 in figure $1 b$ into the sum of paths $1 \rightarrow 2$ and $2 \rightarrow 4$ ). Actual conversion of the metastable solid state 2 to final state 4 would require in this case an irreversible non-adiabatic process at constant $P$ and $S$ leading to a minimization of $H$. The direct path from $1 \rightarrow 4$, on the other hand, is accomplished in a series of infinitesimal reversible adiabatic steps. Although both entropy-conserving and enthalpy-conserving calculations of this sort are conceptually simple, rigorous application of this approach to modelling adiabatic productivity in multicomponent systems would in practice be difficult because of the difficulty of incorporating into the calculation the dependence of the thermodynamic parameters (heat capacities, entropy of fusion, etc.) on changes in melt, solid, and system composition, on residual mineralogy, and on temperature and pressure.

There have been several well-defined thermodynamic treatments of isentropic batch melting of decompressing peridotite (McKenzie 1984; Miller et al. 1991; Albarède 1992; Iwamori et al. 1995). These treatments use as inputs parametrizations of experimental data on isobaric productivity (i.e. $(\partial F / \partial T)_{P}$, where $F$ is the melt fraction), the positions of the solidus and liquidus, and the entropy of fusion (assumed to be constant). These parametrizations are generally poorly constrained (particularly the isobaric productivity near the solidus) and the isentropic productivity

Phil. Trans. R. Soc. Lond. A (1997) 
functions that have been presented are consequently highly variable. For example, McKenzie (1984) favoured models that yield roughly constant or strongly decreasing productivity during upwelling, while Iwamori et al. (1995) and Miller et al. (1991) presented models with complex productivity functions that largely reflect their fits to the solidus and liquidus and to the isobaric productivity function. Note that these treatments cannot easily incorporate the effects on melting of changes in the compositions or abundances of residual phases, of pressure dependent solid-solid phase changes (Asimow et al. 1995a), or of changing bulk composition, and thus, like the simple enthalpy- or entropy-balances described in the preceding paragraphs, they do not provide insight into the influence of these features of peridotite phase equilibria on productivity, which are likely to be substantial. Moreover, these treatments are not well-suited to evaluating the productivity of fractional fusion.

We have adopted in our work (Hirschmann et al. 1994; Baker et al. 1995; Asimow et al. 1995a, b) an approach based on a self-consistent thermodynamic model of multicomponent liquid-crystal equilibria. Using a modification of the MELTS code (Ghiorso \& Sack 1995), we minimize directly the enthalpy for a specific bulk composition at a given $P$ and $S$. Because this treatment incorporates internally consistent thermochemical models for the liquid and solid phases in mantle peridotites, it implicitly takes into account the phase and compositional changes that occur on melting of peridotite without having to incorporate them into parametrizations for the solidus and liquidus, the isobaric productivity etc., which in natural peridotite are unlikely to be fit by simple or general functional forms. In addition, because the model is not linked to any particular bulk composition on which experiments have been conducted, it is equally applicable to batch and fractional melting and can be applied to a range of fertile through depleted peridotite compositions. Though the accuracy of MELTS predictions is at present imperfect, it has been shown to capture even some relatively subtle features of available melting experiments on peridotite (Hirschmann et al. 1994; Baker et al. 1995), and it thus is a promising vehicle for modelling peridotite phase equilibria and melting energetics. Contrary to the results of all previous treatments, MELTS predicts that isentropic productivity strongly increases with progressive melting; e.g. initial melting of a fertile peridotite is predicted to be extremely unproductive, with near-solidus isentropic productivity values near $0.25 \% \mathrm{kbar}^{-1}$, rising to values of $c a .3 \% \mathrm{kbar}^{-1}$ near the exhaustion of clinopyroxene (figure 7; see also Hirschmann et al. 1994; Asimow et al. 1995a).

\section{Isentropic melting in simple systems}

Given the wide range in productivity functions that have been proposed for melting during adiabatic decompression-ranging from constant (Turcotte \& Ahern 1978; Klein \& Langmuir 1987; Scott \& Stevenson 1989; Niu \& Batiza 1991; Sparks \& Parmentier 1991; Kinzler \& Grove 1992), to decreasing as melting proceeds (McKenzie 1984; McKenzie \& Bickle 1988; McKenzie \& Bickle 1990; Langmuir et al. 1992; Longhi 1992), to increasing as melting proceeds (Hirschmann et al. 1994; Asimow et al. 1995a,b), to complex and irregular (McKenzie 1984; McKenzie \& O'Nions 1991; Miller et al. 1991; Iwamori et al. 1995) - it is fair to say that this phenomenon is poorly understood. In order to develop a more complete understanding of the relationship between melting energetics, phase equilibria, and productivity, in this section we examine the behaviour of melting during isentropic upwelling of simple model systems. The melting behaviour of these systems is easy to understand, yet surprisingly rich in insights that can be generalized to multicomponent systems. These

Phil. Trans. R. Soc. Lond. A (1997) 
simple systems thus provide a framework for understanding the productivity during upwelling of more complex natural systems. A key conclusion is going to be that the melting behaviour of these simple systems strongly suggests that the productivity functions generated by the MELTS calculations capture at least qualitatively the behaviour of the real mantle.

In the following discussions we consider both isentropic batch melting and fractional fusion; fractional fusion is envisioned as a sequence of infinitesimal isentropic melting steps, each followed by extraction of the melt phase, carrying its entropy out of the system with it. Both processes are defined by the restriction

$$
\mathrm{d} \boldsymbol{S}=S^{\mathrm{l}} \mathrm{d} \boldsymbol{M}
$$

i.e. the only changes we allow in the entropy of the system, $\boldsymbol{S}$ (extensive variables are boldface), are due to extraction of liquid and the resulting change is given by the specific entropy of the liquid, $S^{\mathrm{l}}$, times the change in system mass, $\boldsymbol{M}$. The general forms we derive will apply to isentropic batch and incrementally isentropic fractional fusion as well as to any continuous melting or dynamic melting process (Langmuir et al. 1977) subject to the restriction that liquid mass is a function of no variables other than solid mass (e.g. $\boldsymbol{M}^{\mathrm{l}}=0$ for fractional fusion; $\boldsymbol{M}^{\mathrm{l}}=\boldsymbol{M}^{0}-\boldsymbol{M}^{\mathrm{s}}$ where $\boldsymbol{M}^{0}$ is the initial system mass, a constant, for batch fusion; and

$$
\boldsymbol{M}^{1}= \begin{cases}\boldsymbol{M}^{0}-\boldsymbol{M}^{\mathrm{s}}, & \text { for } \boldsymbol{M}^{\mathrm{s}} \geqslant\left(1-f^{*}\right) \boldsymbol{M}^{0}, \\ \frac{f^{*}}{1-f^{*}} \boldsymbol{M}^{\mathrm{s}}, & \text { for } \boldsymbol{M}^{\mathrm{s}} \leqslant\left(1-f^{*}\right) \boldsymbol{M}^{0},\end{cases}
$$

for continuous fusion where $f^{*}$ is a constant retained melt fraction). Note that $\boldsymbol{M}^{1}$ refers to the mass of liquid remaining in the system; extracted liquid is considered no further. We use the quantity $F$ to refer to the melt fraction by mass normalized to original source mass for all melting processes:

$$
F=1-\frac{M^{\mathrm{s}}}{M^{0}}
$$

and the quantity $f$ to refer to the mass fraction of liquid that remains in the source region,

$$
f=\frac{M^{1}}{M^{1}+M^{\mathrm{s}}},
$$

i.e. for batch melting, $f=F$; for fractional melting, $f=0$; and for continuous melting as defined in equation (3.2), $f=F$ until $F$ reaches $f^{*}$ and $f=f^{*}$ thereafter.

\section{(a) One-component systems}

The isentropic behaviour of a one-component system can be evaluated rigorously in a closed form. Taking $P$ and $T$ as the independent variables, for a single phase of one component we write

$$
\mathrm{d} S^{\phi}=\left(\frac{\partial S^{\phi}}{\partial T}\right)_{P} \mathrm{~d} T+\left(\frac{\partial S^{\phi}}{\partial P}\right)_{T} \mathrm{~d} P=\frac{C_{p}^{\phi}}{T} \mathrm{~d} T-V^{\phi} \alpha^{\phi} \mathrm{d} P,
$$

where $S$ is specific entropy, $C_{p}$ is isobaric heat capacity, $V$ is specific volume, $\alpha$ is the isobaric coefficient of thermal expansion, and the superscript $\phi$ indicates the properties of a single phase. If we consider two phases, solid (s) and liquid (l), coexisting 
at equilibrium along a univariant curve (denoted $2 \phi$ ), then for coexisting solid and liquid we have

$$
\left(\frac{\mathrm{d} S^{\mathrm{s}}}{\mathrm{d} P}\right)_{2 \phi}=\frac{C_{p}^{\mathrm{s}}}{T}\left(\frac{\mathrm{d} T}{\mathrm{~d} P}\right)_{2 \phi}-V^{\mathrm{s}} \alpha^{\mathrm{s}}
$$

and

$$
\left(\frac{\mathrm{d} S^{\mathrm{l}}}{\mathrm{d} P}\right)_{2 \phi}=\frac{C_{p}^{\mathrm{l}}}{T}\left(\frac{\mathrm{d} T}{\mathrm{~d} P}\right)_{2 \phi}-V^{\mathrm{l}} \alpha^{1} .
$$

For upwelling of a closed system at constant total specific entropy, $S_{0}$, the system must always satisfy

$$
F S^{\mathrm{l}}+(1-F) S^{\mathrm{s}}=S_{0}
$$

Hence for batch melting

$$
F=\frac{S_{0}-S^{\mathrm{s}}}{S^{\mathrm{l}}-S_{s}}=\frac{S_{0}-S^{\mathrm{s}}}{\Delta S_{\mathrm{fus}}}
$$

where $\Delta S_{\text {fus }}$ is the specific entropy of fusion for a one-component system, which is in general a function of $P$ and $T$.

\section{(i) Constant coefficients}

In the special case that $\Delta S_{\text {fus }}$ is constant (equivalent to requiring $C_{p}^{\mathrm{l}}=C_{p}^{\mathrm{s}}$ and $\left.V^{\mathrm{l}} \alpha^{\mathrm{l}}=V^{\mathrm{s}} \alpha^{\mathrm{s}}\right)$, the isentropic productivity for batch melting can be obtained by differentiation of equation (3.8):

$$
-\left(\frac{\partial F}{\partial P}\right)_{S}=\frac{1}{\Delta S_{\text {fus }}}\left(\frac{C_{p}^{\mathrm{s}}}{T}\left(\frac{\mathrm{d} T}{\mathrm{~d} P}\right)_{2 \phi}-V^{\mathrm{s}} \alpha^{\mathrm{s}}\right)=\frac{1}{\Delta S_{\text {fus }}}\left(\frac{C_{p}^{\mathrm{s}}}{T}\left(\frac{\Delta V_{\mathrm{fus}}}{\Delta S_{\mathrm{fus}}}\right)-V^{\mathrm{s}} \alpha^{\mathrm{s}}\right),
$$

where the second equality follows from the Clausius-Clapeyron equation for a onecomponent system. Since melting occurs over a range of pressure along a univariant curve with a finite slope, it also occurs over a range of temperatures. Hence equation (3.9) shows that even in the simplest possible case - a one-component system with constant $\Delta S_{\text {fus }}, \Delta V_{\text {fus }}, C_{p}^{\mathrm{s}}$ and $V^{\mathrm{s}} \alpha^{\mathrm{s}}$-isentropic productivity is not constant; i.e. it depends on temperature.

The magnitude of this effect can be estimated as follows. Neglecting the temperature difference due to the finite slope of the solid adiabat, the ratio of the temperature at the onset of isentropic melting to that at the completion of melting in a system with constant coefficients can be approximated by

$$
\frac{T_{0}}{T_{1}}=\exp \left(\frac{\Delta S_{\text {fus }}}{C_{p}^{\mathrm{l}}}\right)
$$

(Miller et al. 1991). If we take as typical values of the entropy of fusion $c a$. $R$ per atom and of the liquid heat capacity $c a$. $3 R$ per atom, we obtain $T_{0} / T_{1} \sim 1.4$. For most silicates the $V^{\mathrm{s}} \alpha^{\mathrm{s}}$ term in equation (3.9) is very small, so melting at the completion of isentropic melting in a one-component system would typically be $c a .1 .4$ times more productive than at the onset of melting.

Although fractional melting is neither isentropic nor reversible, as indicated above we define an idealized adiabatic fractional melting process as a series of infinitesimal isentropic melting steps, each followed by complete extraction of the liquid, carrying its entropy out of the system. We note that each infinitesimal increment of melting is equivalent to the initial increment of batch melting of a system that has been

Phil. Trans. R. Soc. Lond. A (1997) 
reduced by a factor $(1-F)$ from the original mass of the system. Since $F$ is defined as the mass fraction of the original system that is now liquid (equation (3.3)), we obtain

$$
-\left(\frac{\mathrm{d} F}{\mathrm{~d} P}\right)_{\text {fractional }}=\frac{1}{\Delta S_{\text {fus }}}\left(\frac{C_{p}^{\mathrm{s}}}{T}\left(\frac{\Delta V_{\text {fus }}}{\Delta S_{\text {fus }}}\right)-V^{\mathrm{s}} \alpha^{\mathrm{s}}\right)(1-F)
$$

(for a more rigorous derivation of productivity for incrementally isentropic processes, see the Appendix). Thus, in a one-component system, productivity during fractional melting is initially the same as that of batch melting, but becomes steadily smaller (and asymptotically approaches zero as the system approaches 100\% melt) as upwelling proceeds. We emphasize that in a one-component system with constant coefficients, productivity during fractional fusion defined this way differs from batch productivity solely because of decreasing source mass. Note that the productivity per unit mass of solid, another way to define productivity, is always equal for batch and fractional melting in a one-component system with constant $\Delta S_{\text {fus }}$ (except in the case of solid-solid phase changes; see Asimow et al. (1995a)).

We can obtain an expression suitable for batch and fractional melting, as well as intermediate processes, in which some but not all of the melt is left in the system (socalled continuous or dynamic melting; Langmuir et al. 1977) if we note that at any time the fraction of the original mass that remains in the system is $(1-F) /(1-f)$. For batch melting this term is equal to one, and for fractional melting it reduces to $(1-F)$. Thus, for the general process of isentropic melting steps possibly followed by some melt extraction in the constant-coefficient one-component case (see the Appendix for a more rigorous derivation),

$$
-\left(\frac{\mathrm{d} F}{\mathrm{~d} P}\right)=\frac{1}{\Delta S_{\text {fus }}}\left(\frac{C_{p}^{\mathrm{s}}}{T}\left(\frac{\Delta V_{\text {fus }}}{\Delta S_{\text {fus }}}\right)-V^{\mathrm{s}} \alpha^{\mathrm{s}}\right) \frac{(1-F)}{(1-f)} .
$$

We will generally refer to $-(\mathrm{d} F / \mathrm{d} P)$ as the 'isentropic productivity' even though for fractional fusion the process is only isentropic in each infinitesimal melting step.

To illustrate melting behaviour in a one-component system, equations (3.9) and (3.11) have been applied to pure diopside (we neglect any incongruent melting behaviour; Biggar \& O'Hara 1969; Kushiro 1972). Using the properties given in table 1 and taking the values of $\Delta S_{\text {fus }}, \Delta V_{\text {fus }}, C_{p}^{\mathrm{s}}$ and $V^{\mathrm{s}} \alpha^{\mathrm{s}}$ at the 1 bar melting point to apply at all $P$ and $T$, we obtained a linear melting curve (figure $2 a$ ). The same phase relations are shown in $S-P$ space in figure $2 b$, where it should be noted that although the entropy difference between coexisting solid and liquid is constant, the boundaries of the two-phase field are not linear, reflecting the $1 / T$ dependence in equations (3.6) (Asimow et al. 1995a). Choosing an isentrope that intersects the melting curve at $7 \mathrm{GPa}$, we obtained the productivity curves shown in figure $2 c$ for batch and fractional melting (for comparison, the hypothetical linear case is also shown), which have been integrated to yield the $F$ versus $P$ curves shown in figure $2 d$. Batch melting in this case yields a concave-up $F$ versus $P$ curve, while the curve for fractional melting is concave down. Productivity at the completion of batch melting in this case is a factor 1.6 higher than the initial productivity. The upward curvature of the batch melting curve seen here will be referred to below as the ' $1 / T$ effect'. This effect is of only secondary significance in multicomponent systems, but we draw attention to it here in order to illustrate the improbability of constant productivity for any isentropic melting process.

Phil. Trans. R. Soc. Lond. A (1997) 

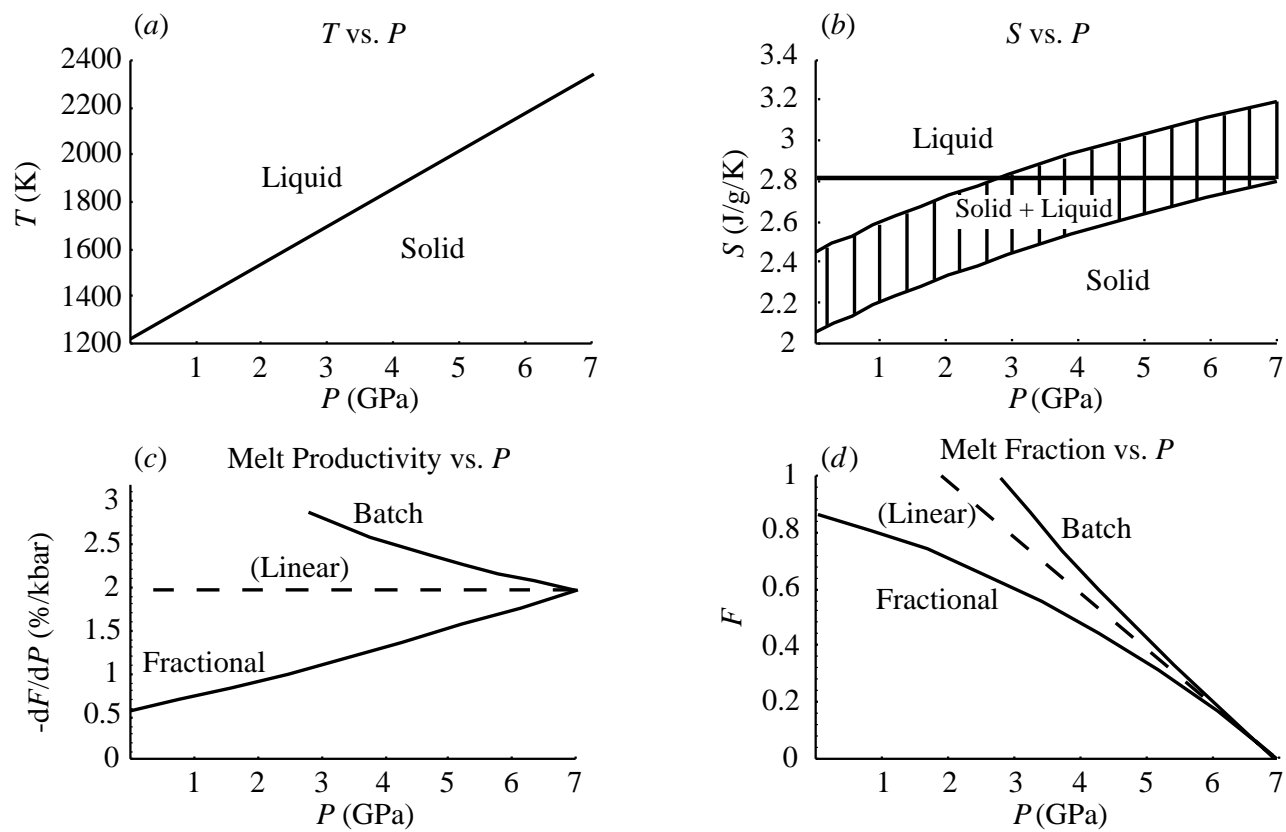

Figure 2. Isentropic melting behaviour of a hypothetical one-component system in which the heat capacity, $(\mathrm{d} V / \mathrm{d} T)_{P}, \Delta V_{\text {fus }}$ and $\Delta S_{\text {fus }}$ of diopside at 1 bar and $1664 \mathrm{~K}$ are taken to obtain over all $P$ and $T$. (a) The solidus is linear. It has been chosen to go through $7 \mathrm{GPa}$ and $2338 \mathrm{~K}$, close to the actual diopside solidus (Rigden et al. 1989). (b) Isentropic melting is best illustrated with an $S-P$ plot. Batch melting follows a horizontal line on this figure. The reference isentrope shown as a heavy horizontal line intersects the solidus at $7 \mathrm{GPa}$. (c) The isentropic productivity (expressed as percent melting per kbar pressure decrement) versus $P$ for batch and fractional paths that intersect the solidus at $7 \mathrm{GPa}$. The dashed line is for comparative purposes only; it does not correspond to any isentropic path. $(d)$ Melt fraction versus $P$ for the same batch and fractional paths.

\section{(ii) Variable coefficients}

Figure $2 c$ shows that for the case of constant coefficients, isentropic melting leads to increasing productivity in the batch case, reflecting the $1 / T$ dependence, and decreasing productivity in the fractional case, reflecting decreasing source mass. We now apply the same analysis using more realistic variations in thermodynamic parameters as functions of $P$ and $T$. In the case that $\Delta S_{\text {fus }}$ is not constant, equations (3.9) and (3.12) do not apply. Instead we begin from equation (3.1) and, as shown in the Appendix, we derive the following general expression for any process of isentropic melting steps possibly followed by melt extraction in a one-component system:

$$
-\left(\frac{\mathrm{d} F}{\mathrm{~d} P}\right)=\frac{1}{\Delta S_{\mathrm{fus}}}\left(\frac{C_{p}^{\mathrm{s}}+f\left(C_{p}^{\mathrm{l}}-C_{p}^{\mathrm{s}}\right)}{T}\left(\frac{\mathrm{d} T}{\mathrm{~d} P}\right)_{2 \phi}-\left[V^{\mathrm{s}} \alpha^{\mathrm{s}}+f\left(V^{\mathrm{l}} \alpha^{1}-V^{\mathrm{s}} \alpha^{\mathrm{s}}\right)\right]\right) \frac{(1-F)}{(1-f)} .
$$

For fractional melting in a one-component system with variable coefficients, $f$ is zero, so equation (3.13) reduces to equation (3.11).

To examine the variable-coefficient case, we again used diopside as the example and treated it as a one-component system. The solidus curve predicted by the thermodynamic data given in table 1 is shown in figure $3 a$; the downward curvature results from the greater compressibility of the liquid relative to the solid. The same phase relations are shown in $S-P$ space in figure $3 b$; the curvature of each boundary

Phil. Trans. R. Soc. Lond. A (1997) 
Table 1. Thermophysical properties of Di (figures 2 and 3) and $a-b$ binary ${ }^{\mathrm{a}}$ (figures 4-6)

\begin{tabular}{cccccc}
\hline parameter & diopside and $a$ solids & $b$ solid & di and $a$ liqs & $b$ liquid & units \\
\hline$S_{0}(298 \mathrm{~K})$ & $142.5^{\mathrm{b}}$ & 174.2 & & & $\mathrm{~J} \mathrm{~mol}^{-1} \mathrm{~K}^{-1}$ \\
$H_{0}(298 \mathrm{~K})$ & $-3200.583^{\mathrm{b}}$ & -2842.221 & & & $\mathrm{~kJ} \mathrm{~mol}^{-1}$ \\
$V_{0}(1664 \mathrm{~K})$ & $69.11^{\mathrm{b}}$ & same & $82.34^{\mathrm{c}}$ & same & $\mathrm{m}^{3} \mathrm{~mol}^{-1} \times 10^{-6}$ \\
$T_{\text {fus }}(1 \mathrm{bar})$ & $1664 \mathrm{~K}$ & $1164 \mathrm{~K}$ & & & \\
$\Delta S_{\text {fus }}(1 \mathrm{bar})$ & $82.88^{\mathrm{e}}$ & same & & & $\mathrm{J} \mathrm{mol}^{-1} \mathrm{~K}^{-1}$ \\
$K_{T 0}$ & $90.7^{\mathrm{c}}$ & same & $21.9^{\mathrm{d}}$ & 24 & $\mathrm{GPa}^{\mathrm{c}}$ \\
$K_{T}^{\prime}$ & $4.5^{\mathrm{c}}$ & same & $6.9^{\mathrm{d}}$ & 6.9 & $\mathrm{~K}^{-1}$ \\
$\alpha$ & $3.2 \times 10^{-5 \mathrm{c}}$ & same & $6.5 \times 10^{-5 \mathrm{c}}$ & same & $\mathrm{J} \mathrm{mol}^{-1} \mathrm{~K}^{-1}$ \\
$C_{p}$ & $305.41-160.49 \mathrm{~T}^{-0.5}$ & same & $353^{\mathrm{c}}$ & same & \\
\multicolumn{7}{c}{$-71.66 \times 10^{5} \mathrm{~T}^{-2}$} & & & & \\
\hline
\end{tabular}

${ }^{a}$ For binary example, end member $a$ is identical to diopside, end member $b$ is selected to have a 1 bar melting point $500 \mathrm{~K}$ lower. Unreferenced quantities for $b$ are chosen arbitrarily to give well-behaved binary phase-loop up to $10 \mathrm{GPa}$.

${ }^{\mathrm{b}}$ Berman (1988).

${ }^{\mathrm{c}}$ Rigden et al. (1989) and sources therein.

${ }^{\mathrm{d}}$ Lange \& Carmichael (1990).

estebbins et al. (1983).

of the two-phase field is higher than in the constant coefficient case, reflecting the $(\mathrm{d} T / \mathrm{d} P)_{2 \phi}$ term in equations (3.6). Using these coefficients, we computed $F(P)$ from equation (3.8) and $-(\mathrm{d} F / \mathrm{d} P)$ from equation (3.13) subject to the constraint $f=F$ along the batch adiabat that intersects the solidus at $7 \mathrm{GPa}$. For fractional melting, we computed $-(\mathrm{d} F / \mathrm{d} P)$ along the path that intersects the solidus at $7 \mathrm{GPa}$ using equation (3.13) subject to the constraint $f=0$, and integrated to obtain $F(P)$. The results are shown in figures $3 c$ and $3 d$.

Comparison of figures $2 c$ and $3 c$ shows that in systems with variable coefficients, the increase in productivity with increasing melt fraction due to the curvature of the solidus can be substantial for batch melting; in the case shown it leads to large (e.g. a factor of 5.7 between $F=0$ and $F=0.9$ ) increases in productivity as melting proceeds. In fact, as shown by comparing the fractional fusion curves in figures $2 c$ and $3 c$, the increase in productivity due to curvature of the solidus in the more realistic case overwhelms the tendency for productivity to decrease due to the decreasing mass of the source and results in increasing productivity with progressive melting even for fractional fusion (although there must be a maximum and productivity must eventually decrease at high melt fraction, since melt fraction normalized by original source mass must for fractional melting asymptotically approach $F=1$ in equation (3.11)). We note that equation (3.13) also shows that a solidus slope that is negative or less than the adiabatic gradient will generally lead to crystallization rather than melting with decreasing pressure at constant entropy (Rumble 1976; Albarède 1983; Iwamori et al. 1995).

The strong increase in productivity in the variable-coefficient one-component case reflects the increase in the slope of the solidus with decreasing pressure. The same effect is present in multicomponent systems, where the analogous controlling variable

Phil. Trans. R. Soc. Lond. A (1997) 

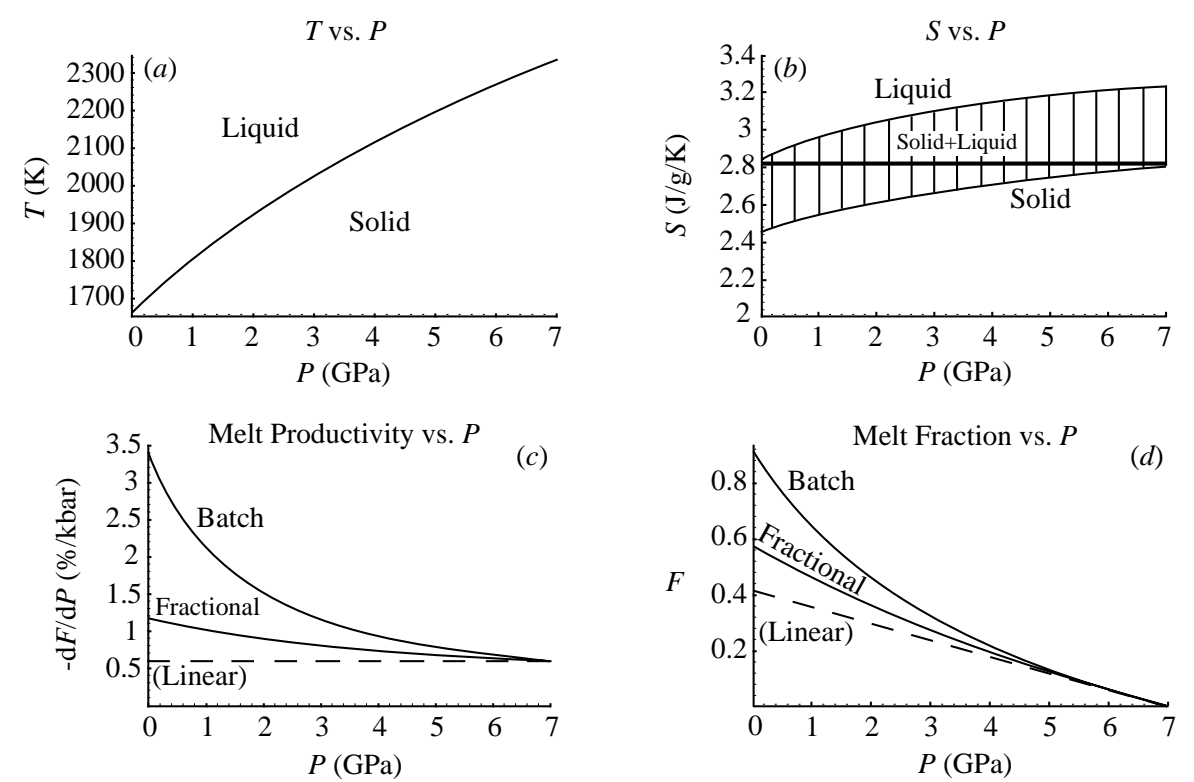

Figure 3. Isentropic melting behaviour of diopside using the thermodynamic data from table 1. (a) The solidus is concave down, due to greater compressibility of the liquid relative to the solid. (b) The curvature of the solidus translates into greater curvature of the edges of the two-phase field in $S-P$ space, compared to figure $2 b$. The heavy horizontal line is an $S-P$ path for batch melting. (c) The isentropic productivity versus $P$ for batch and fractional paths that intersect the solidus at $7 \mathrm{GPa}$. The dashed line is for comparative purposes only; it does not correspond to any isentropic path. $(d)$ Melt fraction versus $P$ for the same batch and fractional paths.

is $(\partial T / \partial P)_{F}$, the slope of a constant melt fraction contour; note that all such contours are collapsed onto the univariant solidus in $P-T$ space in a one-component system but are arrayed between the solidus and the liquidus (and are not, in general, parallel to either) in multicomponent systems. The influence of the slopes of these contours on isentropic productivity will be referred to below as the ' $(\partial T / \partial P)_{F}$ effect'.

\section{(b) Multicomponent systems}

For the general case in a multicomponent system, the expression for $-(\mathrm{d} F / \mathrm{d} P)$ for isentropic or incrementally isentropic melting paths with possible melt extraction is derived in the Appendix:

$$
-\frac{\mathrm{d} F}{\mathrm{~d} P}=\left(\frac{\frac{C_{p}^{\mathrm{s}}+f\left(C_{p}^{\mathrm{l}}-C_{p}^{\mathrm{s}}\right)}{T}\left(\frac{\partial T}{\partial P}\right)_{F}-\left[V^{\mathrm{s}} \alpha^{\mathrm{s}}+f\left(V^{\mathrm{l}} \alpha^{1}-V^{\mathrm{s}} \alpha^{\mathrm{s}}\right)\right]+\left(\frac{\partial S_{X}}{\partial P}\right)_{F}}{\left(C_{p}^{\mathrm{s}}+f\left(C_{p}^{\mathrm{l}}-C_{p}^{\mathrm{s}}\right) / T\left(\frac{\partial F}{\partial T}\right)_{p}\right)+\frac{(1-f)}{(1-F)}\left(S^{\mathrm{l}}-S^{\mathrm{s}}\right)+\left(\frac{\partial S_{X}}{\partial F}\right)_{P}}\right),
$$

where the superscript ' $\mathrm{s}$ ' now refers to the bulk properties of the residual (usually polymineralic) solid assemblage and $\left(\partial S_{X} / \partial P\right)_{F}$ and $\left(\partial S_{X} / \partial F\right)_{P}$ are shorthand notation for terms that reflect the effects on $S^{1}$ and $S^{\mathrm{s}}$ of changes in liquid and mineral composition and of changes in the relative abundances of the minerals in the solid assemblage (see Appendix; for related equations, see Verhoogen 1965; McKenzie 1984;

Phil. Trans. R. Soc. Lond. A (1997) 

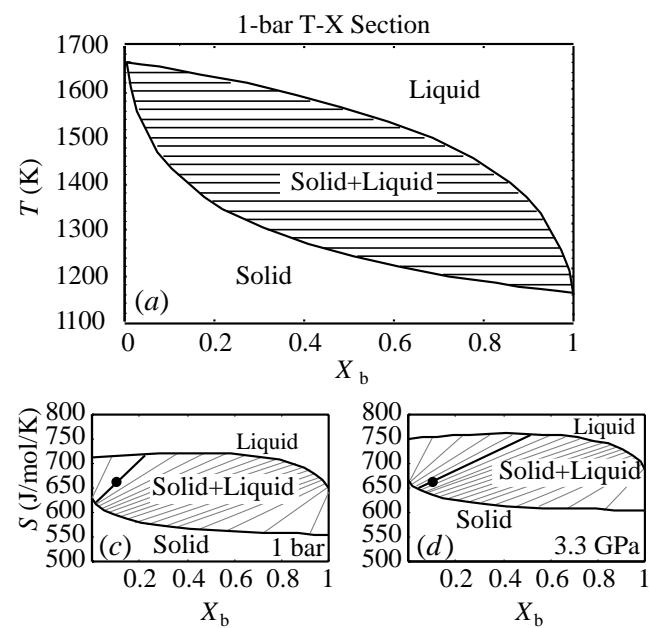
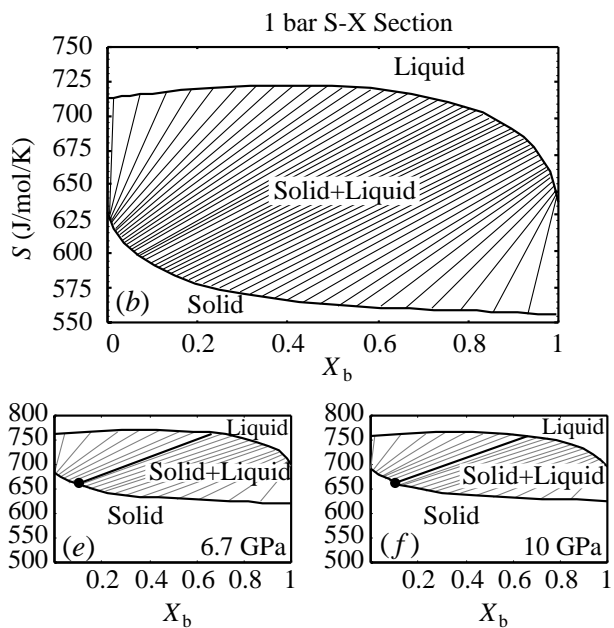

Figure 4. Phase diagram of a two-component model system $a-b$; both solid and liquid are ideal solutions. Model data are in table 1 . (a) $T$ versus $X_{\mathrm{b}}$ at 1 bar. (b) $S$ versus $X_{\mathrm{b}}$ at 1 bar. Tie-lines in the two-phase field indicate entropy and composition of coexisting phases. $(c)-(f)$ Analysis of isentropic melting is visualized by a series of $S$ versus $X_{\mathrm{b}}$ sections at $P=1 \mathrm{bar}, 3.3 \mathrm{GPa}$, 6.7 GPa and $10 \mathrm{GPa}$ with the point $X_{\mathrm{b}}=0.1, S=663 \mathrm{~J} \mathrm{~mol}^{-1} \mathrm{~K}^{-1}$ and the tie-line that passes through it at each pressure highlighted. The position of the point along the highlighted tie-line gives the melt fraction by the lever rule; this sequence illustrates the importance, both of the movement of the phase loop as a function of pressure, and the rotation of the tie-lines towards the vertical near the end members in determining melt fraction and productivity.

Iwamori et al. 1995). Note that $\Delta S_{\text {fus }}$, defined as the entropy difference between a solid and liquid of the same composition, does not appear in this expression. Most earlier thermodynamic treatments of adiabatic melting in multicomponent systems have equated $S^{\mathrm{l}}-S^{\mathrm{s}}$ or $(\partial S / \partial F)_{P, T}$ (which is equivalent to the sum of the last two terms in the denominator of (3.14)) with $\Delta S_{\text {fus }}$ for the bulk peridotite, which has undoubtedly led to inaccuracies. The essential first-order change from equation (3.13) is the presence of a term in the denominator involving the partial derivative of melt fraction with respect to temperature at constant pressure, $(\partial F / \partial T)_{P}$, which we call the isobaric productivity. In a one-component system, isobaric melting occurs at a unique temperature, so this quantity is infinite. Hence the first term in the denominator of equation (3.14) as well as the terms due to compositional and modal changes in the entropy of the phases vanish for one-component systems and this expression reduces to equation (3.13). For multicomponent systems, $(\partial F / \partial T)_{P}$ thus joins $(\partial T / \partial P)_{F}$ as a key source of variability in isentropic productivity. Note that the $1 / T$ effect will typically be of secondary importance in the multicomponent case, since it now contributes both to the numerator and denominator of the expression for $(\mathrm{d} F / \mathrm{d} P)$.

In this section, we explore the origins and importance for isentropic productivity of variations in $(\partial F / \partial T)_{P}$ in a simple two-component binary phase loop and then in MELTS simulations of peridotite melting. We will emphasize that $(\partial F / \partial T)_{P}$ reflects changes in liquid and solid composition during melting via conservation of mass as expressed in the lever rule. We then demonstrate that variations in both $(\partial F / \partial T)_{P}$ and $(\partial T / \partial P)_{F}$ are needed for a reasonably accurate understanding of the variations in $(\mathrm{d} F / \mathrm{d} P)$. We also show that variations of other parameters with melt fraction, including $S^{\mathrm{l}}-S^{\mathrm{s}}$, do not affect productivity variations by more than $c a .10 \%$, even when phases are exhausted from the residue.

Phil. Trans. R. Soc. Lond. A (1997) 
(c) Two-component systems

Before considering isentropic melting, we first evaluate isobaric productivity in two-component systems. We approach the problem in this way because isobaric melting can be treated using familiar phase diagrams from which the effect of composition on productivity can be deduced easily and because we wish to isolate isobaric productivity from the other terms in the general expression for incrementally isentropic productivity (equation (3.14)). In this exercise, we use as a model system a hypothetical binary $a-b$ with complete solid solution in the solid and ideal mixing for both the liquid and solid solutions (figure 4). End member $a$ has the thermodynamic properties of diopside; end member $b$ has similar properties, except the melting point at 1 bar is arbitrarily chosen to be $500{ }^{\circ} \mathrm{C}$ lower than that of $a$. Model parameters for the end members are listed in table 1 . We chose a complete solid solution model as our example, rather than a eutectic or peritectic involving solid phases of fixed composition, because all mantle phases are solid solutions and hence the phase loop captures the essential behaviour of the natural system (except when a phase is exhausted on melting, as discussed later); we chose this hypothetical binary rather than the actual diopside-hedenbergite system because the exaggerated difference in melting points of the two end members allows the effects of a finite melting interval to be more easily seen.

\section{(i) Isobaric melting}

In a two-component system, the productivity of isobaric melting with increasing temperature is simply a matter of conservation of mass. If we consider a system where the bulk composition is given by $X_{\mathrm{b}}$, the mass fraction of component $b$, we can write

$$
F X_{\mathrm{b}}^{1}+(1-F) X_{\mathrm{b}}^{\mathrm{s}}=X_{\mathrm{b}}, \quad \text { or } F=\frac{\left(X_{\mathrm{b}}-X_{\mathrm{b}}^{\mathrm{s}}\right)}{\left(X_{\mathrm{b}}^{\mathrm{l}}-X_{\mathrm{b}}^{\mathrm{s}}\right)},
$$

which is just a statement of mass balance (i.e. the familiar lever rule for graphical analysis of phase diagrams). For batch melting, differentiation of equation (3.15) leads to

$$
\left(\frac{\partial F}{\partial T}\right)_{P}^{\mathrm{batch}}=-\left(\frac{\partial X_{\mathrm{b}}^{\mathrm{s}}}{\partial T}\right)_{P}\left(\frac{1}{X_{\mathrm{b}}^{\mathrm{l}}-X_{\mathrm{b}}^{\mathrm{s}}}\right)-\frac{\left(X_{\mathrm{b}}-X_{\mathrm{b}}^{\mathrm{s}}\right)\left(\partial\left(X_{\mathrm{b}}^{\mathrm{l}}-X_{\mathrm{b}}^{\mathrm{s}}\right) / \partial T\right)_{P}}{\left(X_{\mathrm{b}}^{\mathrm{l}}-X_{\mathrm{b}}^{\mathrm{s}}\right)^{2}} .
$$

For fractional melting the second term in equation (3.16) vanishes since the instantaneous solid composition is always equal to the bulk composition and source mass decreases as $(1-F)$, which leads to

$$
\left(\frac{\partial F}{\partial T}\right)_{P}^{\text {fractional }}=\left(\frac{\partial X_{\mathrm{b}}^{\mathrm{s}}}{\partial T}\right)_{P}\left(\frac{1}{X_{\mathrm{b}}^{\mathrm{l}}-X_{\mathrm{b}}^{\mathrm{s}}}\right)(1-F)
$$

(a more rigorous derivation of the expression for isobaric fractional melting requires starting from extensive variables as in the derivation in the Appendix).

The inverse relationship between isobaric productivity and the compositional difference between coexisting liquid and solid (i.e. the $1 /\left(X_{\mathrm{b}}^{\mathrm{l}}-X_{\mathrm{b}}^{\mathrm{s}}\right)$ factor) is generally the most important term in both equations (3.16) and (3.17) for the simple phase loop. The second term in (3.16) is important at high melt fraction (i.e. where $F=\left(X_{\mathrm{b}}-X_{\mathrm{b}}^{\mathrm{s}}\right) /\left(X_{\mathrm{b}}^{\mathrm{l}}-X_{\mathrm{b}}^{\mathrm{s}}\right)$ is large $)$ or when the solids are fixed or nearly fixed in composition (note that the first term goes to zero if the solid phases are fixed in composition); the derivative of solid composition in the first term is also important near

Phil. Trans. R. Soc. Lond. A (1997) 


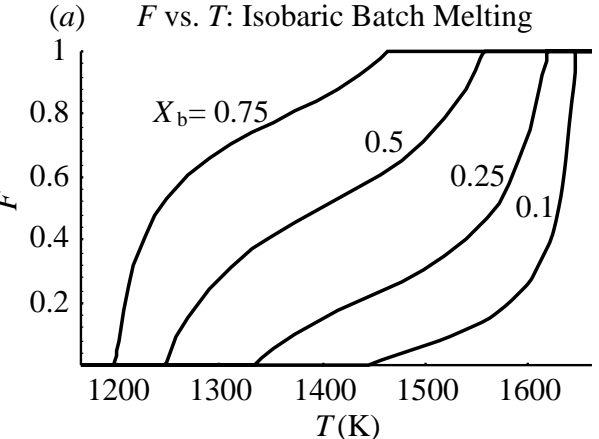

(c) $\mathrm{d} F / \mathrm{d} T$ vs. $T$ : Isobaric Batch Melting

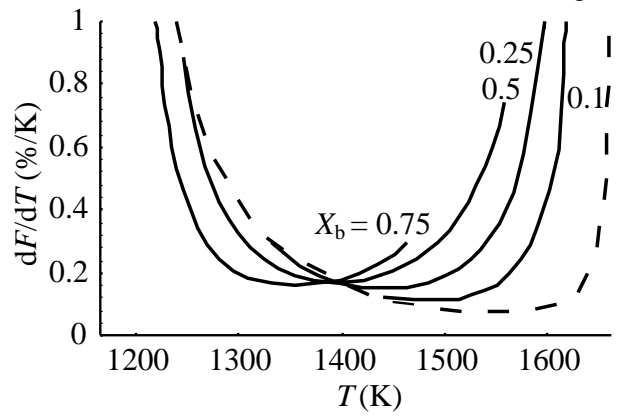

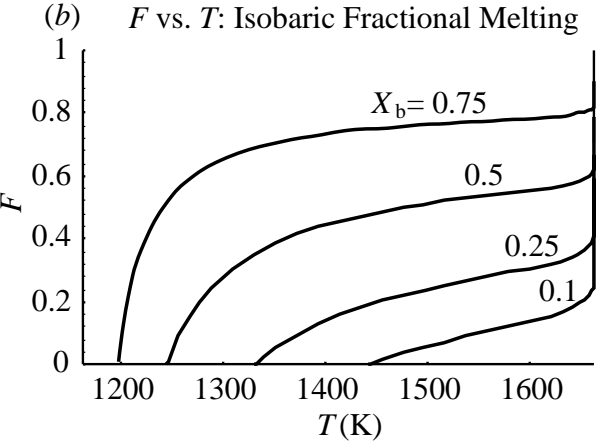

(d) $\mathrm{d} F / \mathrm{d} T$ vs. $T$ : Isobaric Fractional Melting

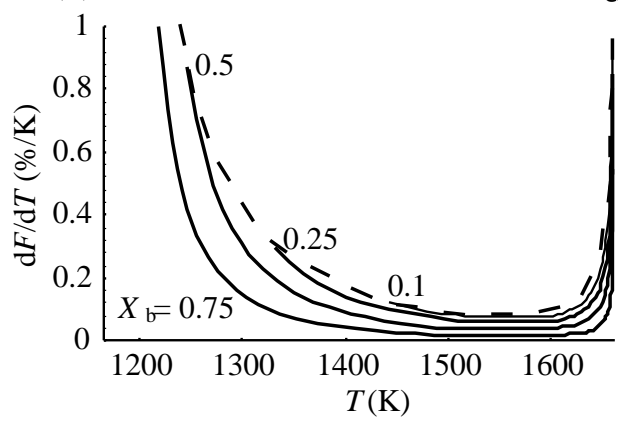

Figure 5. Isobaric batch and fractional melting of the model binary system $a-b$ at 1 bar according to the phase relations shown in figure $4 . X_{\mathrm{b}}$ values indicate the bulk composition of the solid before the initiation of melting. (a) Batch melting, $F$ versus $T$. (b) Fractional melting, $F$ versus $T$. Note that all curves finish melting at $T=1664 \mathrm{~K}$, the melting point of the $a$ end member. $(c)$ Isobaric productivity in percent melting per degree temperature increase for batch melting. The dashed curve shows the first term in equation (3.16) and is the locus of values of productivity on the solidus $(F=0)$ for various bulk compositions. $(d)$ Isobaric productivity for fractional melting. The values differ from the dashed solidus productivity curve only by a factor $(1-F)$.

the exhaustion of a phase from the residue when a multiphase residual assemblage is melting (see below). Equations (3.16) and (3.17) yield infinite $(\partial F / \partial T)_{P}$ during eutectic or peritectic melting.

The key effect of variable composition of the phases is to cause isobaric productivity to be small when the difference between liquid and solid compositions, $\left(X_{\mathrm{b}}^{\mathrm{l}}-X_{\mathrm{b}}^{\mathrm{s}}\right)$, is large. This is illustrated by the quantitative results (figure 5) based on the calculated phase relations for our model binary phase loop (figure 4a), in which the form of the melt fraction versus temperature curve varies with bulk composition mostly according to whether the compositional difference between the liquid and solid initially increases or always decreases with increasing melt fraction. Melt fraction versus temperature curves and isobaric productivity versus temperature curves for batch and fractional melting of the bulk compositions $X_{\mathrm{b}}=0.1,0.25,0.5$ and 0.75 are shown in figure 5 . The dashed curves in figures $5 c$ and $5 d$ plot the first term in equation (3.16); this is the initial isobaric productivity (i.e. at the solidus) as a function of bulk composition. The fractional fusion curves differ from the dashed curve only by a factor $(1-F)$; the batch melting curves differ from the dashed curve according to the second term in equation (3.16), which increases with $F$ and changes sign at the widest point on the phase loop $\left(T=1393 \mathrm{~K}, X_{\mathrm{b}}^{\mathrm{s}}=0.15, X_{\mathrm{b}}^{\mathrm{l}}=0.85\right)$. Examination of the dashed curve in figures $5 c$ and $5 d$ shows that in this example, the multiplication 
by $\left(\partial X_{\mathrm{b}}^{\mathrm{s}} / \partial T\right)_{P}$ in the first term of equation (3.16) contributes a strong asymmetry to the productivity function, which is otherwise dominated by the (nearly symmetric about $1393 \mathrm{~K}$ ) inverse compositional distance term. The net effect of all these terms is that compositions with $X_{\mathrm{b}}<0.06$ show a melt fraction versus temperature curve for batch melting that is always concave up (i.e. an isobaric productivity that always increases as melting proceeds). For fractional melting, productivity always increases for $X_{\mathrm{b}}<0.03$. For more $b$-rich bulk compositions, the melt fraction versus temperature curves (such as those illustrated in figures $5 a$ and $5 b$ for $X_{\mathrm{b}}=0.25,0.5$ and 0.75$)$ are initially concave down, but concave up at higher $F$. The critical bulk $X_{\mathrm{b}}$ below which the melt fraction versus temperature curve is everywhere concave up depends on the shape of the phase loop; in the diopside-hedenbergite system where the phase loop is much narrower, it occurs at $X_{\mathrm{Hd}} \sim 0.4$ for batch melting and $X_{\mathrm{Hd}} \sim 0.2$ for fractional melting. In the forsterite-fayalite system the corresponding values are $X_{\mathrm{Fa}} \sim 0.14$ for batch melting and $X_{\mathrm{Fa}} \sim 0.1$ for fractional melting. The location of this critical $X_{\mathrm{b}}$ cannot be read directly off the phase diagram; it depends on all the terms in equations (3.16) or (3.17) and does not correspond to the widest point on the phase loop. Note again that in the special case where the solid residue is fixed in composition (i.e. only batch melting is continuous in temperature), the first term in equation (3.16) vanishes and the difference in melt and solid composition always decreases with $F$, so the geometric effect leads to the melt fraction versus temperature curve being everywhere concave up.

\section{(ii) Isentropic melting}

There is no simple two-dimensional phase diagram with which to portray isentropic melting for a binary loop. Inspection of the general expression for isentropic melting (equation (3.14)) shows that the geometric effect related to the compositional distance between liquid and solid (i.e. the $(\partial F / \partial T)_{P}$ term discussed in the preceding paragraphs) is superimposed on the $1 / T$ and $(\partial T / \partial P)_{F}$ effects that control isentropic productivity in one-component systems. The relationship among the terms in these equations can be visualized by examining figures $4 b-f$. Figure $4 b$ shows $S$ versus $X_{\mathrm{b}}$ at 1 bar for the model binary phase loop; figures $4 c-f$ show a series of simplified $S$ versus $X_{\mathrm{b}}$ sections on the same scale at successively higher pressures. With increasing pressure, the entire phase loop moves up (i.e. to higher values of specific entropy); in the one-component diopside-like end member $a$, this increase is illustrated in figure $3 b$. Isentropic melting of a particular bulk composition can then be visualized as the movement of the loop over a particular fixed point $\left(X_{\mathrm{b}}=0.1\right.$, $S=663 \mathrm{~J} \mathrm{~mol}^{-1} \mathrm{~K}^{-1}$ in this example) as pressure decreases.

Although the shape of the phase loop is complex and changes with pressure, its overall downward movement with decreasing pressure tends to contribute, for any composition, to increasing productivity with decreasing $P$ (i.e. a concave up $F$ versus $P$ diagram) just as it does in the one-component end members. This reflects the $1 / T$ and $(\partial T / \partial P)_{F}$ dependencies described above. The melt composition effect is discernible in the rotation of the tie lines (in this case little influenced by decompression) towards the vertical from the center to the edges of the loop, which results in changes in the difference in composition between the solid and liquid with increased melting. Although it is not as easy to read as the diagrams for the isobaric melting case, examination of figure 4 shows that for $a$-rich compositions, the compositional difference between solid and melt decreases with decreasing pressure (and increasing melt fraction). Just as in the isobaric melting case, this leads to a purely geometric contribution tending to increase productivity as pressure decreases. However,

Phil. Trans. R. Soc. Lond. A (1997) 
Isentropic Melting of Two Component System: $\mathrm{X}_{\mathrm{b}}=0.1$
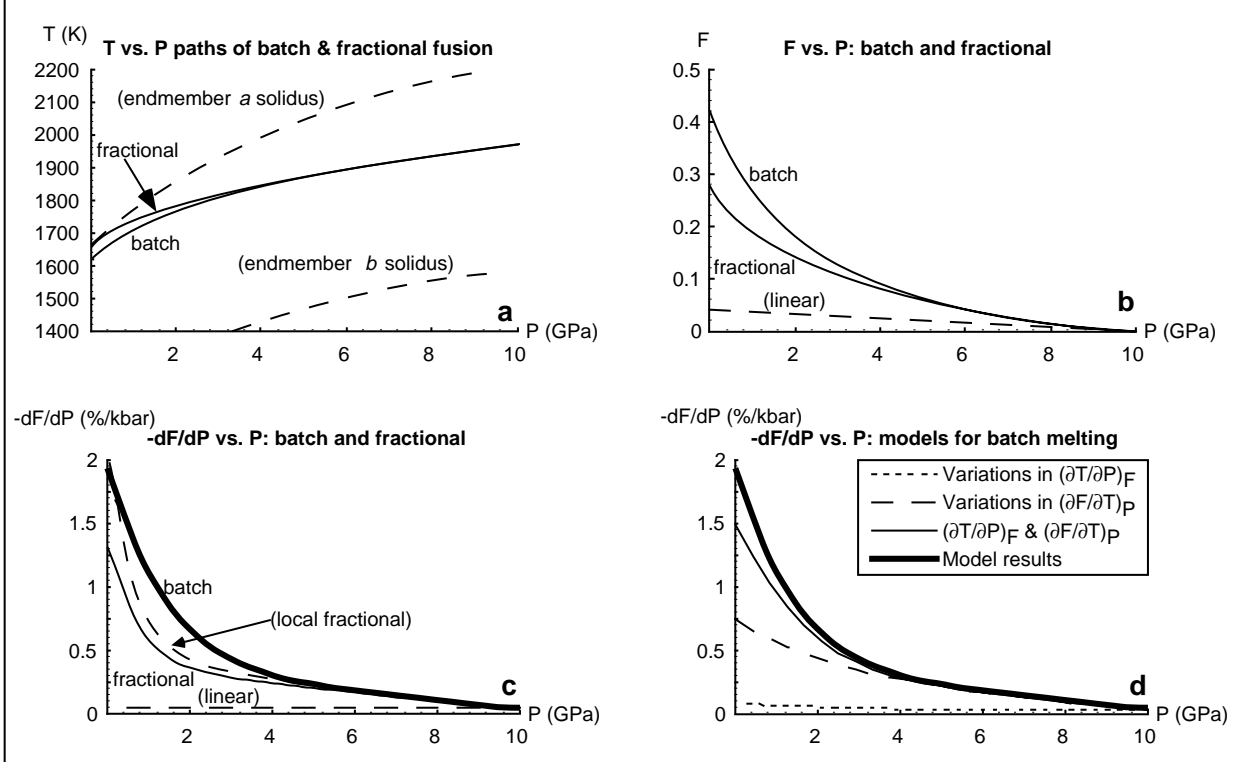

Figure 6. Isentropic batch and incrementally isentropic fractional melting of the model binary system $a-b$. (a) $T$ versus $P$, showing the univariant melting curves for the end members and both batch and fractional isentropic melting paths for composition $a_{90} b_{10}$ that intersect the solidus at $10 \mathrm{GPa}$. (b) $F$ versus $P$, showing the upward curvature characteristic of increasing productivity. The dashed line is a linear extrapolation of the productivity at the solidus; it does not correspond to any isentropic path. (c) Isentropic productivity versus $P$ for batch and fractional melting. The dashed curve shows 'local' fractional productivity of a unit mass of solid at any pressure; the light solid curve shows $-\mathrm{d} F / \mathrm{d} P$ for incrementally isentropic fractional melting, where $F$ is normalized to the original source mass (see text). $(d)$ Isentropic productivity versus $P$ for batch melting (heavy curve) compared to a calculation (light solid curve) of productivity based on equation (3.14) where all parameters except $(\partial T / \partial P)_{F}$ and $(\partial F / \partial T)_{P}$ were held constant at their values on the solidus at $10 \mathrm{GPa}$ (see text for details). Also shown are calculations in which we allowed $(\partial T / \partial P)_{F}$ (dotted curve) or $(\partial F / \partial T)_{P}$ (dashed curve) to vary along the adiabat, holding the other quantity constant at its solidus value. Variations in $(\partial F / \partial T)_{P}$ capture the major qualitative features of the productivity, but $(\partial T / \partial P)_{F}$ variations are also required to get a good quantitative fit.

for more $b$-rich compositions, the compositional difference between solid and liquid initially increases with progressive isentropic melting; as a consequence, when this increase is quite pronounced, complex melt fraction versus $P$ functions (including initially decreasing productivity) can result from the combination of this with the $1 / T$ and $(\partial T / \partial P)_{F}$ effects.

Results for isentropic melting in the model binary system are shown in figure 6 for isentropic batch and fractional melting of the bulk composition $a_{90} b_{10}$ starting at $10 \mathrm{GPa}$. As anticipated in the above discussion of figures $4 c-f$, isentropic productivity increases with progressive melting. For fractional melting, figure $6 c$ shows both the productivity normalized to original source mass, the usage we adopt, and the productivity relative to unit mass of solid present at any pressure (dotted line, labelled 'local fractional'). It is interesting to note that (except exactly at the solidus where they are identical) the local productivity of fractional melting in this system is lower than the productivity of batch melting at low melt fraction but slightly greater at

Phil. Trans. R. Soc. Lond. A (1997) 
high melt fraction (similar to models of peridotite melting; Hirschmann et al. 1994). Comparison of figures 5 and 6 shows that the contribution of the $(\partial T / \partial P)_{F}$ effect can lead to increasing isentropic productivity at all $F$ even for compositions such as $X_{\mathrm{b}}=0.1$ that have initially decreasing isobaric productivity.

To demonstrate the contributions of the $(\partial T / \partial P)_{F}$ and $(\partial F / \partial T)_{P}$ terms to variations in isentropic productivity, we calculated productivity curves by substituting these quantities into equation (3.14), assuming all other parameters $\left(C_{p}^{\mathrm{s}}, C_{p}^{\mathrm{l}}, T, f\right.$, $V^{\mathrm{s}} \alpha^{\mathrm{s}}, V^{\mathrm{l}} \alpha^{\mathrm{l}}$ and $\left.\left(S^{\mathrm{l}}-S^{\mathrm{s}}\right)\right)$ are constant at their values on the solidus at $10 \mathrm{GPa}$ (although $(1-F) /(1-f)$ is also allowed to vary so that fractional melting is normalized properly and all terms due to compositional and modal changes in the entropy of the phases, i.e. $\left(\partial S_{X} / \partial P\right)_{F}$ and $\left(\partial S_{X} / \partial F\right)_{P}$, are set to zero). We also tried allowing only one of $(\partial T / \partial P)_{F}$ and $(\partial F / \partial T)_{P}$ to vary and holding the other constant along with the above list of parameters at its value on the solidus; the resulting three curves (labelled according to which quantity or quantities we allowed to vary) are shown in figure $6 d$. Only when we allow both $(\partial T / \partial P)_{F}$ and $(\partial F / \partial T)_{P}$ to vary do we reproduce the isentropic productivity function reasonably well, demonstrating that variations of both parameters control the detailed shape of the productivity function. Note that the chosen bulk composition in this model system has a total isobaric melting interval (i.e. an average $\left.(\partial F / \partial T)_{P}\right)$ for $0.1<X_{\mathrm{b}}<0.9$ comparable to that of natural peridotite (Takahashi 1986); hence the quantitative importance of $(\partial F / \partial T)_{P}$ relative to other sources of productivity variation in equation (3.14) in this two-component system is comparable to its importance in peridotite melting.

\section{(d) Multicomponent systems}

Equation (3.14) shows how knowledge of $(\partial F / \partial T)_{P},(\partial T / \partial P)_{F}$, and values of parameters such as $\left(S^{\mathrm{l}}-S^{\mathrm{s}}\right), C_{p}, T$ and $V \alpha$ can be translated into predictions of isentropic productivity and its variability for any system of arbitrary compositional complexity and variance. There are, however, factors other than those we have considered in the model systems treated above that contribute to the variability of these parameters and thus to variations in productivity during isentropic melting. For example, we have emphasized that the dominant term for isobaric melting along a binary phase loop is the inverse dependence on the compositional distance between liquid and solid. However, discontinuous reactions and phase exhaustion must also play important roles in productivity for polymineralic assemblages. We have not presented simple examples involving such phenomena, but they are readily treated in terms of the same parameters discussed above. For example, the exhaustion of a phase restricts the compositional variations available to the solid residue. This translates into a discontinuous drop in the rate of change of the composition of the solid with temperature (equivalent to the $\left(\partial X_{\mathrm{b}}^{\mathrm{s}} / \partial T\right)_{P}$ term in equations $(3.16)$ and (3.17)) and therefore results in a discontinuous drop in productivity even though the compositional distance (equivalent to $X_{\mathrm{b}}^{1}-X_{\mathrm{b}}^{\mathrm{s}}$ in equations (3.16) and (3.17)) is continuous. The effect of the derivative of bulk solid composition on productivity is also evident at the end of eutectic or peritectic melting in a simple system (where the change from infinite $\left(\partial X_{\mathrm{b}}^{\mathrm{s}} / \partial T\right)_{P}$ and $(\partial F / \partial T)_{P}$ to finite values results in a corresponding decrease in $-\mathrm{d} F / \mathrm{d} P$ in equation (3.14)), at the loss of a phase during cotectic melting in a ternary system, and at the exhaustion of clinopyroxene during melting of natural peridotite. Note that in none of our simulations of batch fusion have we observed a drop in productivity except on phase exhaustion (or addition, as in the case of the spinel-plagioclase transition (Asimow et al. 1995a)).

Phil. Trans. R. Soc. Lond. A (1997) 

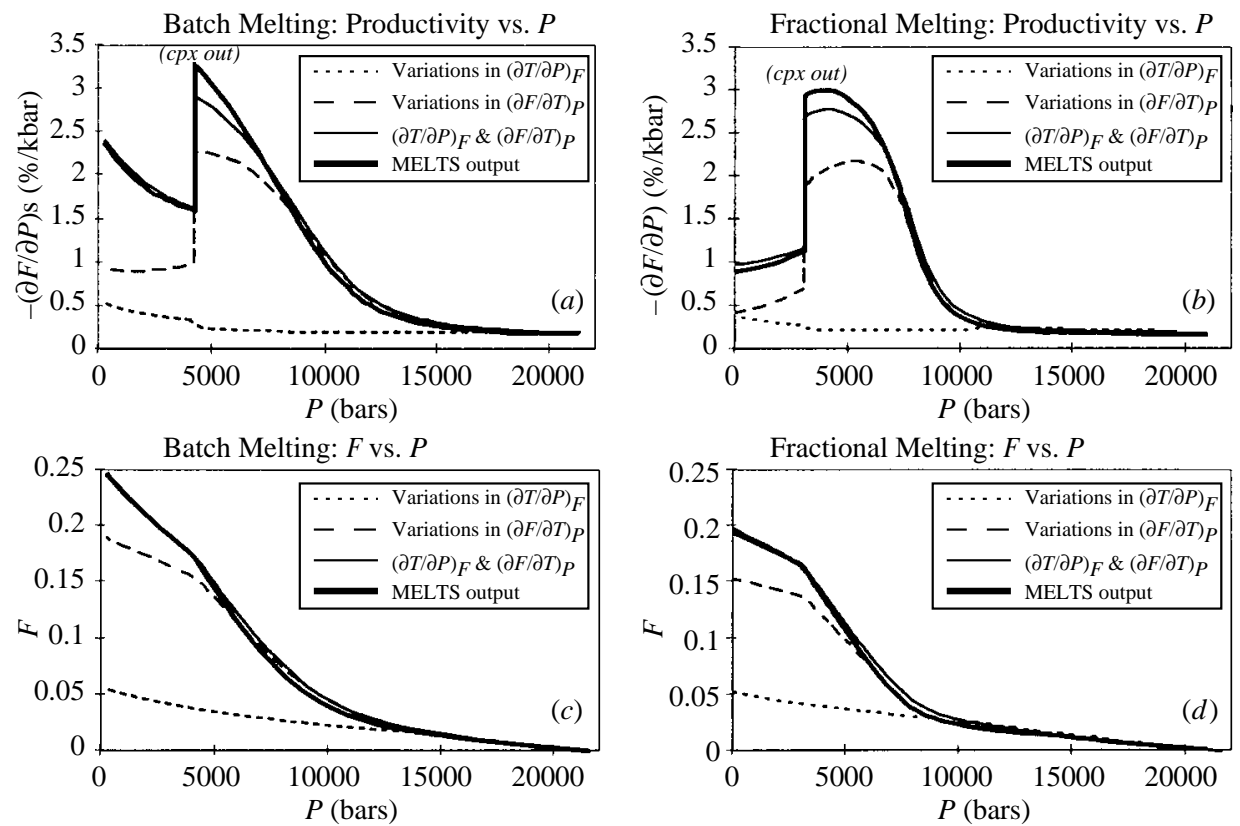

Figure 7. Isentropic melting of 9-component model fertile peridotite (Hart \& Zindler 1986; Asimow et al. 1995a) based on calculations using MELTS. (a) Isentropic productivity versus $P$ during batch melting (heavy curve) compared with productivity predicted by equation (3.14) with all parameters except (i) $(\partial T / \partial P)_{F}$ (dotted curve), (ii) $(\partial F / \partial T)_{P}$ (dashed curve), or (iii) $(\partial T / \partial P)_{F}$ and $(\partial F / \partial T)_{P}$ (light solid curve) held constant at their values near the middle of the melting paths at $11 \mathrm{kbar}$ (see text for details). (b) Analogous to (a) for fractional melting. $(c)$ Melt fraction $F$ versus $P$ for batch melting, compared to melt fraction expected by integrating the three curves in $(a)$. $(d)$ Analogous to $(c)$ for fractional melting.

\section{Model peridotite system}

Given the simple rules developed above for one- and two-component systems and their generalization to multicomponent systems, we are now in a position to anticipate the productivity function of isentropically melting mantle peridotite during batch fusion and of incrementally isentropic fractional fusion. Although a rigorous analysis is needed to understand the interaction of all the variables controlling productivity in a complex multicomponent system, the simple arguments developed here give considerable insight into the overall behaviour. For example, our analysis makes clear that isentropic productivity is very unlikely ever to be even approximately constant. In addition, it suggests that the concave up melt fraction versus $P$ functions predicted for peridotite melting by the MELTS algorithm (Hirschmann et al. 1994; Asimow et al. 1995a) are robust features of the behaviour of natural peridotite.

We have examined quantitatively controls on productivity using the results of isentropic batch and fractional MELTS calculations on a model peridotite. We used a nine-component model composition in the system $\mathrm{SiO}_{2}-\mathrm{TiO}_{2}-\mathrm{Al}_{2} \mathrm{O}_{3}-\mathrm{Cr}_{2} \mathrm{O}_{3}-\mathrm{Fe}_{2} \mathrm{O}_{3}-$ $\mathrm{FeO}-\mathrm{MgO}-\mathrm{CaO}-\mathrm{Na}_{2} \mathrm{O}$ (composition from Hart \& Zindler 1986). Choosing an adiabat that intersects the solidus at $22 \mathrm{kbar}$, we calculated batch melting by minimizing $H$ at fixed $S, P$ and bulk composition to obtain $T, F$ and the compositions of coexisting liquid and solids. For fractional fusion, we searched in pressure for the point along the isentrope that has a fixed incremental melt fraction $(\mathrm{d} F=0.001)$ and then took the entropy and composition of the residue as the reference for the next step. Batch

Phil. Trans. R. Soc. Lond. A (1997) 
isentropic productivity was calculated by differentiation of the $F$ versus $P$ results, and fractional productivity was determined by dividing $\mathrm{dF}$ by the pressure difference between successive melt extractions. Figure 7 shows the calculated productivity and melt fraction as functions of pressure for batch and fractional melting.

We have evaluated the extent to which the sources of variation isolated above (i.e. $(\partial T / \partial P)_{F}$ and $\left.(\partial F / \partial T)_{P}\right)$ combine to control variations in MELTS-predicted peridotite productivity via an exercise similar to the analysis of the binary case above. We assumed all other parameters $\left(C_{p}^{\mathrm{s}}, C_{p}^{\mathrm{l}}, T, f, V^{\mathrm{s}} \alpha^{\mathrm{s}}, V^{\mathrm{l}} \alpha^{1}\right.$ and $\left(S^{\mathrm{l}}-S^{\mathrm{s}}\right)$ but not $(1-F) /(1-f)$, which normalizes fractional melting, or $\left(\partial S_{X} / \partial P\right)_{F}$ and $\left(\partial S_{X} / \partial F\right)_{P}$, which we neglect altogether by setting them to zero) in equation (3.14) to be constant (at their $11 \mathrm{kbar}$ values, i.e. at the midpoint of the melting paths) and calculated the isentropic productivity along the melting path based on several different sets of values for $(\partial T / \partial P)_{F}$ and $(\partial F / \partial T)_{P}$ : (i) the actual value of $(\partial T / \partial P)_{F}$ at each point on the melting path, with $(\partial F / \partial T)_{P}$ held constant at its 11 kbar value; (ii) the actual value of $(\partial F / \partial T)_{P}$ at each point on the melting path, with $(\partial T / \partial P)_{F}$ held constant at its $11 \mathrm{kbar}$ value; and (iii) the actual values of both $(\partial T / \partial P)_{F}$ and $(\partial F / \partial T)_{P}$ along the melting path. The resulting curves are shown in figure 7 , labelled by what was allowed to vary. For both batch and fractional fusion, shown in figures $7 a$ and $7 b$, case (ii) captures the general form of the isentropic productivity function, including the rise to a peak at the exhaustion of clinopyroxene and the sharp drop-off. Case (iii), however, shows much better quantitative agreement (although differences are noticeable where productivity is large), demonstrating as for the binary case presented earlier that variations in both $(\partial T / \partial P)_{F}$ and $(\partial F / \partial T)_{P}$ must be taken into account to approximate accurately the productivity function. The fits to melt fraction for case (iii) shown in figures $7 c$ and $7 d$ are also very good, indicating that the overall amounts of melting during batch and fractional fusion of peridotite can be precisely modelled using equation (3.14) and that variations in $T,\left(S_{l}-S_{s}\right), C_{p}, V \alpha$ and compositional derivatives are of secondary importance compared to $(\partial T / \partial P)_{F}$ and $(\partial F / \partial T)_{P}$. We emphasize that this exercise is entirely based on the internally consistent nature of the MELTS calculation; consequently, although it helps to isolate the key parameters in the peridotite productivity function as predicted by MELTS, it does not directly address the accuracy of the MELTS results for melt production in nature.

The good qualitative match to the isentropic productivity obtained solely by varying $(\partial F / \partial T)_{P}$ (figures $7 a$ and $\left.7 b\right)$ implies that the source of much of the variation in isentropic productivity can be understood by examining the controls on $(\partial F / \partial T)_{P}$. Just as in the two-component system discussed above, the shape of the isobaric productivity function reflects the compositions of coexisting melt and residue and is dominated by the rate of change of the compositional difference between them (except near the exhaustion of a phase in the more complex system). Near-solidus melts of peridotite differ significantly in composition from the coexisting residue, and the composition of the liquid changes rapidly with increased melting at low melt fractions, becoming more similar to the composition of the residue with increased melting (e.g. in the sense that the melts become richer in normative olivine and poorer in normative plagioclase and incompatible elements, and thus more similar to peridotite; Takahashi \& Kushiro 1983; Baker \& Stolper 1994; Kushiro 1996). Our analysis indicates that this 'geometric effect', which influences the $(\partial F / \partial T)_{P}$ function and hence the isentropic productivity, is the main factor leading to low productivity near the solidus and the strongly concave up melt fraction versus pressure function predicted 
by the MELTS calculations. It must be emphasized that peridotite melting is neither invariant nor pseudo-invariant (there are many more components than phases and hence in both MELTS calculations and experiments the compositions of liquids vary continuously at all melt fractions) and thus eutectic and peritectic melting are very poor models for peridotite. The important point is that the increase in isentropic productivity with progressive melting in these calculations is dominated by the tendency for the liquids to be initially very distant from the source composition (due especially to high concentrations of incompatible elements like $\mathrm{Na}_{2} \mathrm{O}$ ) and to move towards the bulk composition with progressive melting.

As illustrated by figure 7 , the discontinuous changes in isentropic productivity associated with phase exhaustion are also precisely mirrored by changes in isobaric productivity; in both cases this reflects the rate of change of the residual solid composition (analogous to the $\left(\partial X_{\mathrm{b}}^{\mathrm{s}} / \partial T\right)_{P}$ parameter in equations (3.16) and (3.17)). As the exhaustion of clinopyroxene is approached during batch melting, the bulk residual solid composition changes significantly and its temperature derivative is large; the result is a very high productivity in this region. At the actual disappearance of clinopyroxene from the residue, the derivative of bulk solid composition decreases discontinuously, resulting in a drop in productivity. In the fractional case, the shape of the productivity function just before clinopyroxene exhaustion is somewhat different (figure $7 a$ versus $7 b$; note that this difference is not apparent in the $F$ versus $P$ figures, figure $7 c$ versus $7 d$ ); the decrease in productivity in anticipation of clinopyroxene exhaustion during fractional fusion probably reflects the fact that the jadeite component of clinopyroxene is nearly exhausted a few kbar before the phase disappears, leading to a decrease in the temperature derivative of clinopyroxene composition and hence a decrease in both isobaric and isentropic productivity in advance of the much larger discontinuous drop at cpx-out. This example illustrates quite clearly a point made in the Introduction, that efforts to model or understand the productivity of peridotite melting, that do not include the effects of phase equilibria and changing solid and liquid compositions as melting progresses, are very unlikely to capture the essence of the isentropic melting process.

The predicted overall increase in isentropic productivity with melt fraction in the batch melting case, punctuated by drops in productivity upon exhaustion of phases from the residue, appears to be a general feature of simple systems with solidsolution, particularly when the solid solution(s) are close to the high-temperature end member(s). MELTS calculations suggest that it is also a robust feature of the more complex multicomponent peridotite system. The productivity function for fractional fusion can be more complex, but it is also likely to have a concave upward shape at low degrees of melting of relatively fertile peridotite. Note that productivity during fractional fusion of fertile peridotite, although lower than that of batch fusion at low melt fraction (but not exactly at the solidus, where they must be equal), is predicted to be comparable to that of batch fusion after several percent melting (figures $7 a$ and $7 b$; see also Hirschmann et al. 1994). Although contrary to most previous speculations (Niu \& Batiza 1991; Langmuir et al. 1992), recent experimental work appears to confirm this prediction (Hirose \& Kawamura 1994).

\section{Conclusions}

There is no thermodynamic basis for assuming a constant rate of melt generation during isentropic depressurization. Even in a simple one-component system, the isentropic productivity depends on $1 / T$ and the slope of the solidus, leading to increasing

Phil. Trans. R. Soc. Lond. A (1997) 
productivity with progressive melting (i.e. the melt fraction versus pressure function is concave up). Although other parameters appear in the general expression for isentropic productivity in multicomponent systems, the most important factors are the slopes of equal melt-fraction contours, $(\partial T / \partial P)_{F}$, and the isobaric productivity, $(\partial F / \partial T)_{P}$, both of which can be determined, in principle, from relatively straightforward phase equilibrium experiments. The isobaric productivity is the principal source of the variability of productivity during isentropic melting of peridotite, and it can be reduced to a simple statement of mass balance if the compositions of coexisting melt and residue are known. At low melt fractions, changes in the isobaric melt productivity are dominated by the decrease with progressive melting in the compositional difference between liquid and bulk residual solids.

Several authors have constructed models of peridotite melting in which $(\partial F / \partial T)_{P}$ is initially very high and decreases with progressive melting, based largely on analogy with low variance melting in simple systems (e.g. at a eutectic or peritectic). Thermodynamic modelling using MELTS, however, does not predict such behaviour. In contrast, initial liquids are predicted to differ significantly in composition from the coexisting bulk solid and to move closer in composition to the residue with progressive melting, leading to low productivity at the solidus and increases in productivity with increasing melt fraction (i.e. the same variations in productivity found for analogous simple systems). The same effects carry over into isentropic productivity. There are additional complexities related to phase changes and phase exhaustions, but their impact on isentropic productivity can also be understood by examining these same effects.

In summary, analysis of simple systems and thermodynamic calculations on complex peridotite compositions lead us to predict that isentropic melting of typical mantle peridotites will be characterized by an overall increase in isentropic productivity with melt fraction in the batch melting case, punctuated by drops in productivity upon exhaustion of each phase from the residue. The productivity function for fractional fusion can be more complex, but we predict that the concave upward shape of the melt fraction versus pressure curve predicted for the batch fusion case is also likely to be a characteristic of low degrees of fractional melting of relatively fertile peridotite.

The authors are grateful to Mark Ghiorso and Richard Sack, the authors of MELTS, for permission to play with their code and suit it to our needs. Mike O'Hara provided a helpful review and much important devil's advocacy. This work was supported by NSF grants OCE-9504517, EAR9219899 and OCE-9314505. This is Division of Geological and Planetary Sciences contribution 5703.

\section{Appendix A.}

Here we derive a general expression for isentropic and for incrementally isentropic melt productivity in multicomponent systems. We consider only processes that obey the restriction

$$
\mathrm{d} \boldsymbol{S}=S^{\mathrm{l}} \mathrm{d} \boldsymbol{M}
$$

where $\boldsymbol{S}$ is the extensive entropy of the system, $S^{1}$ is the specific entropy of the liquid phase, and $\boldsymbol{M}$ is the mass of the system. We also require that the mass of liquid in the source region, $\boldsymbol{M}^{1}$, be a function only of the mass of solid in the source region,

Phil. Trans. R. Soc. Lond. A (1997) 
$\boldsymbol{M}^{\mathrm{s}}$, and constants such that

$$
\frac{\mathrm{d} \boldsymbol{M}^{\mathrm{l}}}{\mathrm{d} \boldsymbol{M}^{\mathrm{s}}}=\left(\frac{\partial \boldsymbol{M}^{\mathrm{l}}}{\partial \boldsymbol{M}^{\mathrm{s}}}\right)_{Y} \quad \text { and } \quad\left(\frac{\partial \boldsymbol{M}^{\mathrm{l}}}{\partial Y}\right)_{\boldsymbol{M}^{\mathrm{s}}}=0
$$

for any variable $Y$. For multicomponent systems, the superscript s refers to bulk properties of the polymineralic solid assemblage. These constraints limit the processes to those for which entropy change of the system only occurs by extraction of melt and for which there is a strict coupling between melt production and melt extraction. For example, for batch fusion, $\mathrm{d} \boldsymbol{M}=0$ (i.e. $\mathrm{d} \boldsymbol{M}^{\mathrm{l}}=-\mathrm{d} \boldsymbol{M}^{\mathrm{s}}$ ), so equation (A 1) means that the process is isentropic. For fractional fusion, the mass of the system decreases due to removal of liquid (i.e. $\mathrm{d} \boldsymbol{M}=\mathrm{d} \boldsymbol{M}^{\mathrm{s}}$ ), and the entropy of the system decreases by the amount carried away by the liquid; since this is the only way in which the entropy of the system changes, fractional fusion subject to the constraint of equation (A 1) can be envisioned as a series of infinitesimal increments of isentropic fusion followed by complete melt removal.

Given equations (A 1) and (A 2), the changes in the state of the system are entirely determined by two variables, so we can write the total differential of $\boldsymbol{S}$ in terms of $P$ and $\boldsymbol{M}^{\mathrm{s}}$ :

$$
\mathrm{d} \boldsymbol{S}=\left(\frac{\partial \boldsymbol{S}}{\partial P}\right)_{\boldsymbol{M}^{\mathrm{s}}} \mathrm{d} P+\left(\frac{\partial \boldsymbol{S}}{\partial \boldsymbol{M}^{\mathrm{s}}}\right)_{P} \mathrm{~d} \boldsymbol{M}^{\mathrm{s}}
$$

Since $\boldsymbol{M}=\boldsymbol{M}^{\mathrm{l}}+\boldsymbol{M}^{\mathrm{s}}$, equations (A 1) and (A 3) lead to

$$
\left(\frac{\partial \boldsymbol{S}}{\partial P}\right)_{\boldsymbol{M}^{\mathrm{s}}} \mathrm{d} P+\left(\frac{\partial \boldsymbol{S}}{\partial \boldsymbol{M}^{\mathrm{s}}}\right)_{P} \mathrm{~d} \boldsymbol{M}^{\mathrm{s}}=S^{\mathrm{l}} \mathrm{d} \boldsymbol{M}^{\mathrm{l}}+S^{\mathrm{l}} \mathrm{d} \boldsymbol{M}^{\mathrm{s}} .
$$

Dividing equation (A 4) by $\mathrm{d} P$, rearranging, and applying the chain rule

$$
\frac{\mathrm{d} \boldsymbol{M}^{1}}{\mathrm{~d} P}=\frac{\mathrm{d} \boldsymbol{M}^{1}}{\mathrm{~d} \boldsymbol{M}^{\mathrm{s}}} \frac{\mathrm{d} \boldsymbol{M}^{\mathrm{s}}}{\mathrm{d} P}
$$

leads to an expression for the change in solid mass with pressure:

$$
\frac{\mathrm{d} \boldsymbol{M}^{\mathrm{s}}}{\mathrm{d} P}=\left(\frac{\partial \boldsymbol{S}}{\partial P}\right)_{\boldsymbol{M}^{\mathrm{s}}} /\left[S^{\mathrm{l}}+S^{\mathrm{l}} \frac{\mathrm{d} \boldsymbol{M}^{\mathrm{l}}}{\mathrm{d} \boldsymbol{M}^{\mathrm{s}}}-\left(\frac{\partial \boldsymbol{S}}{\partial \boldsymbol{M}^{\mathrm{s}}}\right)_{P}\right] .
$$

We now evaluate the partial derivatives that appear in equation (A 6). We differentiate

$$
\boldsymbol{S}=\boldsymbol{M}^{\mathrm{s}} S^{\mathrm{s}}+\boldsymbol{M}^{\mathrm{l}} S^{\mathrm{l}}
$$

to obtain

$$
\left(\frac{\partial \boldsymbol{S}}{\partial P}\right)_{\boldsymbol{M}^{\mathrm{s}}}=\boldsymbol{M}^{\mathrm{s}}\left(\frac{\partial S^{\mathrm{s}}}{\partial P}\right)_{\boldsymbol{M}^{\mathrm{s}}}+\boldsymbol{M}^{\mathrm{l}}\left(\frac{\partial S^{\mathrm{l}}}{\partial P}\right)_{\boldsymbol{M}^{\mathrm{s}}}+S^{\mathrm{l}}\left(\frac{\partial \boldsymbol{M}^{\mathrm{l}}}{\partial P}\right)_{\boldsymbol{M}^{\mathrm{s}}} .
$$

The restriction, equation (A 2), causes the last term in equation (A 8) to vanish. The evaluation of the remaining terms in equation (A 8) is related to equations $(3.6 a)$ and $(3.6 b)$ in the text, except that partial derivatives at constant $\boldsymbol{M}^{\mathrm{s}}$ appear in place of total derivatives along the two-phase boundary, and more importantly we must now include derivatives that describe changes in the compositions of the phases:

$$
\mathrm{d} S^{\mathrm{l}}=\left(\frac{\partial S^{\mathrm{l}}}{\partial T}\right)_{P, X^{1}} \mathrm{~d} T+\left(\frac{\partial S^{\mathrm{l}}}{\partial P}\right)_{T, X^{1}} \mathrm{~d} P+\sum_{i=1}^{n^{1}}\left(\frac{\partial S^{\mathrm{l}}}{\partial X_{i}^{\mathrm{l}}}\right)_{T, P, X_{j \neq i}^{1}} \mathrm{~d} X_{i}^{\mathrm{l}},
$$

Phil. Trans. R. Soc. Lond. A (1997) 


$$
\mathrm{d} S^{\mathrm{s}}=\left(\frac{\partial S^{\mathrm{s}}}{\partial T}\right)_{P, X^{\mathrm{s}}} \mathrm{d} T+\left(\frac{\partial S^{\mathrm{s}}}{\partial P}\right)_{T, X^{\mathrm{s}}} \mathrm{d} P+\sum_{k=1}^{n^{\mathrm{s}}}\left[S^{k} \mathrm{~d} \gamma^{k}+\gamma^{k} \sum_{i=1}^{n^{k}}\left(\frac{\partial S^{k}}{\partial X_{i}^{k}}\right)_{T, P, X_{j \neq 1}^{k}} \mathrm{~d} X_{i}^{k}\right],
$$

where $X_{i}^{1}$ is the mass fraction of component $i$ in the $n^{1}$ component liquid phase and

$$
\left(\frac{\partial S^{1}}{\partial X_{i}^{1}}\right)_{T, P, X_{j \neq i}^{1}}
$$

should be recognized as the partial specific entropy of component $i$ in the liquid. In $($ A $9 b), S^{\text {s }}$ represents a weighted sum over $n^{\mathrm{s}}$ solid phases, $\gamma^{k}$ is the mass fraction of the $k$ th solid phase in the bulk assemblage, $S^{k}$ is the specific entropy of the $k$ th phase, $X_{i}^{k}$ is the mass fraction of component $i$ in the $k$ th solid phase of $n^{k}$ components, and

$$
\left(\frac{\partial S^{k}}{\partial X_{i}^{k}}\right)_{T, P, X_{j \neq i}^{k}}
$$

is the partial specific entropy of component $i$ in solid phase $k$. All these new quantities are, in general, functions of temperature, pressure and bulk composition. For brevity in what follows we define the entire last term in (A $9 a)$ as $\mathrm{d} S_{X}^{\mathrm{l}}$ and the entire last term in (A $9 b)$ as d $S_{X}^{\mathrm{s}}$, since they represent the changes in $S^{\mathrm{l}}$ and $S^{\mathrm{s}}$ due to compositional and/or modal changes in the liquid and bulk solid, respectively. We note that these terms have been neglected without comments in all previous treatments of isentropic melting of which we are aware. In most cases, first-order approximations of productivity remain reasonable when $\mathrm{d} S_{X}^{\mathrm{l}}$ and $\mathrm{d} S_{X}^{\mathrm{s}}$ are neglected.

From (A $9 a)$ and $(\mathrm{A} 9 b)$ we can obtain

$$
\begin{aligned}
& \left(\frac{\partial S^{\mathrm{l}}}{\partial P}\right)_{M^{\mathrm{s}}}=\frac{C_{p}^{\mathrm{l}}}{T}\left(\frac{\partial T}{\partial P}\right)_{M^{\mathrm{s}}}-V^{\mathrm{l}} \alpha^{1}+\left(\frac{\partial S_{X}^{\mathrm{l}}}{\partial P}\right)_{M^{\mathrm{s}}}, \\
& \left(\frac{\partial S^{\mathrm{s}}}{\partial P}\right)_{\boldsymbol{M}^{\mathrm{s}}}=\frac{C_{p}^{\mathrm{s}}}{T}\left(\frac{\partial T}{\partial P}\right)_{\boldsymbol{M}^{\mathrm{s}}}-V^{\mathrm{s}} \alpha^{\mathrm{s}}+\left(\frac{\partial S_{X}^{\mathrm{s}}}{\partial P}\right)_{\boldsymbol{M}^{\mathrm{s}}},
\end{aligned}
$$

where the last terms are abbreviations for sums similar to those in (A $9 a$ ) and (A $9 b)$ except $\left(\partial X_{i}^{1} / \partial P\right)_{\boldsymbol{M}^{\mathrm{s}}}$ is substituted for $\mathrm{d} X_{i}^{\mathrm{l}},\left(\partial \gamma^{k} / \partial P\right)_{\boldsymbol{M}^{\mathrm{s}}}$ for $\mathrm{d} \gamma^{k}$, and $\left(\partial X_{i}^{k} / \partial P\right)_{\boldsymbol{M}^{\mathrm{s}}}$ for $\mathrm{d} X_{i}^{k}$. Using the intensive variable $f=\boldsymbol{M}^{\mathrm{l}} /\left(\boldsymbol{M}^{\mathrm{l}}+\boldsymbol{M}^{\mathrm{s}}\right)$ for the mass fraction of liquid in the system and combining equations (A 8), (A $9 c$ ) and (A $9 d$ ) leads to

$$
\begin{aligned}
\left(\frac{\partial S}{\partial P}\right)_{\boldsymbol{M}^{\mathrm{s}}} & =\left(\boldsymbol{M}^{\mathrm{s}}+\boldsymbol{M}^{\mathrm{l}}\right)\left(\frac{C_{p}^{\mathrm{s}}+f\left(C_{p}^{\mathrm{l}}-C_{p}^{\mathrm{s}}\right)}{T}\left(\frac{\partial T}{\partial P}\right)_{\boldsymbol{M}^{\mathrm{s}}}\right. \\
& \left.-\left[V^{\mathrm{s}} \alpha^{\mathrm{s}}+f\left(V^{\mathrm{l}} \alpha^{1}-V^{\mathrm{s}} \alpha^{\mathrm{s}}\right)\right]+f\left(\frac{\partial S_{X}^{\mathrm{l}}}{\partial P}\right)_{\boldsymbol{M}^{\mathrm{s}}}+(1-f)\left(\frac{\partial S_{X}^{\mathrm{s}}}{\partial P}\right)_{\boldsymbol{M}^{\mathrm{s}}}\right),
\end{aligned}
$$

and below for brevity we will use the definition

$$
\left(\frac{\partial S_{X}}{\partial P}\right)_{M^{\mathrm{s}}} \equiv f\left(\frac{\partial S_{X}^{\mathrm{l}}}{\partial P}\right)_{\boldsymbol{M}^{\mathrm{s}}}+(1-f)\left(\frac{\partial S_{X}^{\mathrm{s}}}{\partial P}\right)_{\boldsymbol{M}^{\mathrm{s}}} .
$$

Next we take the partial derivative of equation (A 7) with respect to $\boldsymbol{M}^{\mathrm{s}}$ at constant $P$ :

$$
\left(\frac{\partial \boldsymbol{S}}{\partial \boldsymbol{M}^{\mathrm{s}}}\right)_{P}=S^{\mathrm{s}}+S^{\mathrm{l}}\left(\frac{\partial \boldsymbol{M}^{\mathrm{l}}}{\partial \boldsymbol{M}^{\mathrm{s}}}\right)_{P}+\boldsymbol{M}^{\mathrm{s}}\left(\frac{\partial S^{\mathrm{s}}}{\partial \boldsymbol{M}^{\mathrm{s}}}\right)_{P}+\boldsymbol{M}^{\mathrm{l}}\left(\frac{\partial S^{\mathrm{l}}}{\partial \boldsymbol{M}^{\mathrm{s}}}\right)_{P} .
$$

Phil. Trans. R. Soc. Lond. A (1997) 
To simplify equation (A 11) we can obtain from (A $9 a$ ) and (A $9 b)$ :

$$
\left.\begin{array}{l}
\left(\frac{\partial S^{\mathrm{l}}}{\partial \boldsymbol{M}^{\mathrm{s}}}\right)_{P}=\frac{C_{p}^{\mathrm{l}}}{T}\left(\frac{\partial T}{\partial \boldsymbol{M}^{\mathrm{s}}}\right)_{P}+\left(\frac{\partial S_{X}^{\mathrm{l}}}{\partial \boldsymbol{M}^{\mathrm{s}}}\right)_{P} \\
\left(\frac{\partial S^{\mathrm{s}}}{\partial \boldsymbol{M}^{\mathrm{s}}}\right)_{P}=\frac{C_{p}^{\mathrm{s}}}{T}\left(\frac{\partial T}{\partial \boldsymbol{M}^{\mathrm{s}}}\right)_{P}+\left(\frac{\partial S_{X}^{\mathrm{s}}}{\partial \boldsymbol{M}^{\mathrm{s}}}\right)_{P},
\end{array}\right\}
$$

where again the last terms in each expression are defined similarly to the last terms in (A $9 a)$ and (A $9 b)$ except that partial derivatives with respect to $\boldsymbol{M}^{\mathrm{s}}$ at constant $P$ replace all the total differentials, which together with the definition of $f$ and (A 2) lead to

$$
\begin{aligned}
\left(\frac{\partial \boldsymbol{S}}{\partial \boldsymbol{M}^{\mathrm{s}}}\right)_{P} & =S^{\mathrm{s}}+S^{\mathrm{l}} \frac{\partial \boldsymbol{M}^{\mathrm{l}}}{\partial \boldsymbol{M}^{\mathrm{s}}} \\
& +\left(\boldsymbol{M}^{\mathrm{s}}+\boldsymbol{M}^{\mathrm{l}}\right)\left(\frac{C_{p}^{\mathrm{s}}+f\left(C_{p}^{\mathrm{l}}-C_{p}^{\mathrm{s}}\right)}{T\left(\partial \boldsymbol{M}^{\mathrm{s}} / \partial T\right)_{P}}+f\left(\frac{\partial S_{X}^{\mathrm{l}}}{\partial \boldsymbol{M}^{\mathrm{s}}}\right)_{P}+(1-f)\left(\frac{\partial S_{X}^{\mathrm{s}}}{\partial \boldsymbol{M}^{\mathrm{s}}}\right)_{P}\right),
\end{aligned}
$$

and for further brevity we define

$$
\left(\frac{\partial S_{X}}{\partial \boldsymbol{M}^{\mathrm{s}}}\right)_{P} \equiv f\left(\frac{\partial S_{X}^{\mathrm{l}}}{\partial \boldsymbol{M}^{\mathrm{s}}}\right)_{P}+(1-f)\left(\frac{\partial S_{X}^{\mathrm{s}}}{\partial \boldsymbol{M}^{\mathrm{s}}}\right)_{P} .
$$

We now substitute equations (A 10) and (A 13) into (A 6) to obtain our final expression in terms of extensive mass variables:

$$
-\frac{\mathrm{d} \boldsymbol{M}^{\mathrm{s}}}{\mathrm{d} P}=\frac{\frac{C_{p}^{\mathrm{s}}+f\left(C_{p}^{\mathrm{l}}-C_{p}^{\mathrm{s}}\right)}{T}\left(\frac{\partial T}{\partial P}\right)_{\boldsymbol{M}^{\mathrm{s}}}-\left[V^{\mathrm{s}} \alpha^{\mathrm{s}}+f\left(V^{\mathrm{l}} \alpha^{1}-V^{\mathrm{s}} \alpha^{\mathrm{s}}\right)\right]+\left(\frac{\partial S_{X}}{\partial P}\right)_{\boldsymbol{M}^{\mathrm{s}}}}{\left(\frac{C_{p}^{\mathrm{s}}+f\left(C_{p}^{\mathrm{l}}-C_{p}^{\mathrm{s}}\right)}{T\left(\partial \boldsymbol{M}^{\mathrm{s}} / \partial T\right)_{P}}\right)-\frac{\left(S^{\mathrm{l}}-S^{\mathrm{s}}\right)}{\left(\boldsymbol{M}^{\mathrm{s}}+\boldsymbol{M}^{\mathrm{l}}\right)}+\left(\frac{\partial S_{X}}{\partial \boldsymbol{M}^{\mathrm{s}}}\right)_{P}},
$$

where we retain $S^{\mathrm{l}}-S^{\mathrm{s}}$ and $\left(\partial S_{x} / \partial \boldsymbol{M}^{\mathrm{s}}\right)_{P}$ instead of attempting to define the last two terms in the denominator as $\Delta S_{\text {fus }}$ since this does not correspond to the common understanding of the meaning of $\Delta S_{\text {fus }}$. Now the definition of $F=1-\left(\boldsymbol{M}^{\mathrm{s}} / \boldsymbol{M}^{0}\right)$, the fraction of the initial solid mass that has been melted, gives

$$
\frac{\mathrm{d} F}{\mathrm{~d} P}=-\frac{1}{\boldsymbol{M}^{0}} \frac{\mathrm{d} \boldsymbol{M}^{\mathrm{s}}}{\mathrm{d} P}, \quad\left(\frac{\partial F}{\partial Y}\right)_{P}=-\frac{1}{\boldsymbol{M}^{0}}\left(\frac{\partial \boldsymbol{M}^{\mathrm{s}}}{\partial Y}\right)_{P} \quad \text { and } \quad\left(\frac{\partial Y}{\partial P}\right)_{F}=\left(\frac{\partial Y}{\partial P}\right)_{\boldsymbol{M}^{\mathrm{s}}},
$$

for any variable $Y$ (including notably $T$ and $S_{X}$, which can be shown using the definitions above), which relations together with the equation $(1-F) /(1-f)=$ $\left(\boldsymbol{M}^{\mathrm{s}}+\boldsymbol{M}^{\mathrm{l}}\right) / \boldsymbol{M}^{0}$ allow us to eliminate all extensive variables from equation (A 14) and produce our final productivity equation:

$$
-\frac{\mathrm{d} F}{\mathrm{~d} P}=\left(\frac{\frac{C_{p}^{\mathrm{s}}+f\left(C_{p}^{\mathrm{l}}-C_{p}^{\mathrm{s}}\right)}{T}\left(\frac{\partial T}{\partial P}\right)_{F}-\left[V^{\mathrm{s}} \alpha^{\mathrm{s}}+f\left(V^{\mathrm{l}} \alpha^{1}-V^{\mathrm{s}} \alpha^{\mathrm{s}}\right)\right]+\left(\frac{\partial S_{X}}{\partial P}\right)_{F}}{\left(\frac{C_{p}^{\mathrm{s}}+f\left(C_{p}^{\mathrm{l}}-C_{p}^{\mathrm{s}}\right)}{T(\partial F / \partial T)_{P}}\right)+\frac{(1-f)}{(1-F)}\left(S^{\mathrm{l}}-S^{\mathrm{s}}\right)+\left(\frac{\partial S_{X}}{\partial F}\right)_{P}}\right) .
$$

Equation (A 16) can be simplified directly for batch and fractional melting by 
taking $F=f$ and $f=0$, respectively. Furthermore, equation (A 16) reduces to the correct form (equation (3.13)) for one-component systems, where (i) it is straightforward to set $\Delta S_{\text {fus }}=\left(S^{\mathrm{l}}-S^{\mathrm{s}}\right)$ and there are no $S_{X}$ terms since composition is constant and only one solid phase can participate in melting except at an invariant point, (ii) the last two terms in equation (A 11) and hence the first term in the denominator of equation (A 16) vanish since $(\partial T / \partial F)_{P}=0$ when isobaric melting takes place at a unique temperature, and (iii) $(\partial T / \partial P)_{F}=(\mathrm{d} T / \mathrm{d} P)_{2 \phi}$ since all melting is restricted to the univariant two-phase curve. Finally, equation (A 16) can be reduced to the constant coefficient one-component case (equation (3.12)) since

$$
\Delta S_{\text {fus }}(P, T)=\Delta S_{\text {fus }}\left(P_{0}, T_{0}\right)+\int_{T_{0}}^{T} \frac{\left(C_{p}^{1}-C_{p}^{\mathrm{s}}\right)}{T} \mathrm{~d} T+\int_{P_{0}}^{P}\left(V^{\mathrm{l}} \alpha^{1}-V^{\mathrm{s}} \alpha^{\mathrm{s}}\right) \mathrm{d} P
$$

means that constant $\Delta S_{\text {fus }}$ also requires $\left(C_{p}^{\mathrm{l}}-C_{p}^{\mathrm{s}}\right)=0$ and $\left(V^{\mathrm{l}} \alpha^{1}-V^{\mathrm{s}} \alpha^{\mathrm{s}}\right)=0$.

We also include here the expression for calculating the $P-T$ path of upwelling material undergoing any of the melting processes described by equations (A 1) and (A 2). For batch melting it is simple to show

$$
\left(\frac{\partial T}{\partial P}\right)_{S}=\left(\frac{\partial T}{\partial P}\right)_{F}+\left(\frac{\partial F}{\partial P}\right)_{S} /\left(\frac{\partial F}{\partial T}\right)_{P}
$$

(e.g. Albarède 1992). A simple derivation beginning from the total differential of $\boldsymbol{M}^{\mathrm{s}}$ expressed in terms of $P$ and $T$ followed by substitution of $F$ for $\boldsymbol{M}^{\mathrm{s}}$ leads to the corresponding result for $(\mathrm{d} T / \mathrm{d} P)$ subject to equation (A 1) rather than constant $S$ :

$$
\frac{\mathrm{d} T}{\mathrm{~d} P}=\left(\frac{\partial T}{\partial P}\right)_{F}+\frac{\mathrm{d} F}{\mathrm{~d} P} /\left(\frac{\partial F}{\partial T}\right)_{P} .
$$

\section{References}

Albarède, F. 1983 Limitations thermiques à l'ascension des magmas hydratés. C. R. Acad. Sci. Paris 296, 1441-1444.

Albarède, F. 1992 How deep do common basaltic magmas form and differentiate? J. Geophys. Res. 97, $10997-11009$.

Asimow, P. D., Hirschmann, M. M., Ghiorso, M. S., O'Hara, M. J. \& Stolper, E. M. $1995 a$ The effect of pressure-induced solid-solid phase transitions on decompression melting of the mantle. Geochim. Cosmochim. Acta 59, 4489-4506.

Asimow, P. D., Hirschmann, M. M., Ghiorso, M. S. \& Stolper, E. M. $1995 b$ Isentropic melting processes in the mantle. In Plume 2 Conf. (ed. D. L. Anderson et al.), pp. 12-14. Terra Nostra 3/1995. Bonn: Alfred-Wegener-Stiftung.

Baker, M. B., Hirschmann, M. M., Ghiorso, M. S. \& Stolper, E. M. 1995 Compositions of lowdegree partial melts of peridotite: Results from experiments and thermodynamic calculations. Nature 375, 308-311.

Baker, M. B. \& Stolper, E. M. 1994 Determining the composition of high-pressure mantle melts using diamond aggregates. Geochim. Cosmochim. Acta 58, 2811-2827.

Berman, R. G. 1988 Internally-consistent thermodynamic data for minerals in the system $\mathrm{Na}_{2} \mathrm{O}-$ $\mathrm{K}_{2} \mathrm{O}-\mathrm{CaO}-\mathrm{MgO}-\mathrm{FeO}-\mathrm{Fe}_{2} \mathrm{O}_{3}-\mathrm{Al}_{2} \mathrm{O}_{3}-\mathrm{SiO}_{2}-\mathrm{TiO}_{2}-\mathrm{H}_{2} \mathrm{O}-\mathrm{CO}_{2}$ : representation, estimation, and high temperature extrapolations. J. Petrol. 89, 168-183.

Biggar, G. M. \& O'Hara, M. J. 1969 Solid solutions at atmospheric pressure in the system CaO$\mathrm{MgO}-\mathrm{SiO}_{2}$ with special reference to the instabilities of diopside, akermanite, and monticellite. Prog. Exp. Pet. pp. 89-96. London: NERC.

Cawthorn, R. G. 1975 Degrees of melting in mantle diapirs and the origin of ultrabasic liquids. Earth Planet. Sci. Lett. 27, 113-120.

Phil. Trans. R. Soc. Lond. A (1997) 
Ghiorso, M. S. \& Sack, R. O. 1995 Chemical mass transfer in magmatic processes. IV. A revised and internally consistent thermodynamic model for the interpolation and extrapolation of liquid-solid equilibria in magmatic systems at elevated temperatures and pressures. Contrib. Mineral. Petrol. 119, 197-212.

Hart, S. R. 1993 Equilibration during mantle melting: A fractal tree model. Proc. Natl. Acad. Sci. 90, 11914-11918.

Hart, S. R. \& Zindler, A. 1986 In search of a bulk-earth composition. Chem. Geol. 57, 247-267.

Hess, P. C. 1992 Phase equilibria constraints on the origin of ocean floor basalt. In Mantle flow and melt generation at mid-ocean ridges (ed. J. Phipps Morgan et al.), pp. 67-102. (Geophysical Monograph 71.) Washington, DC: AGU.

Hirose, K. \& Kawamura, K. 1994 A new experimental approach for incremental batch melting of peridotite at 1.5 GPa. Geophys. Res. Lett. 21, 2139-2142.

Hirschmann, M. M., Stolper, E. M. \& Ghiorso, M. S. 1994 Perspectives on shallow mantle melting from thermodynamic calculations. Min. Mag. A 58, 418-419.

Iwamori, H., McKenzie, D. P. \& Takahashi, E. 1995 Melt generation by isentropic mantle upwelling. Earth Planet. Sci. Lett. 134, 253-266.

Kinzler, R. J. \& Grove, T. L. 1992 Primary magmas of mid-ocean ridge basalts. 2. Applications. J. Geophys. Res. 97, 6907-6926.

Klein, E. M. \& Langmuir, C. H. 1987 Global correlations of ocean ridge basalt chemistry with axial depth and crustal thickness. J. Geophys. Res. 92, 8089-8115.

Kushiro, I. 1972 Determination of liquidus relations in synthetic silicate systems with electron probe analyses: The system forsterite-diopside-silica at 1 atm. Am. Mineral. 57, 51-74.

Kushiro, I. 1996 Partial melting of a fertile mantle peridotite at high pressure: and experimental study using aggregates of diamond. In Earth processes: reading the isotopic clock (ed. A. Basu \& S. Hart), pp. 109-122. (Geophysical Monograph 95.) Washington, DC: AGU.

Lange, R. L. \& Carmichael, I. S. E. 1990 Thermodynamic properties of silicate liquids with emphasis on density, thermal expansion and compressibility. In Modern methods of igneous petrology: understanding magmatic processes (ed. J. Nicholls \& J. K. Russell), Rev., Mineral., no. 24, pp. 25-64. Washington, DC: Mineralogical Society of America.

Langmuir, C. H., Bender, J. F., Bence, A. E., Hanson, G. N. \& Taylor S. R. 1977 Petrogenesis of basalts from the FAMOUS area: Mid-Atlantic Ridge. Earth Planet. Sci. Lett. 36, 133-156.

Langmuir, C. H., Klein, E. M. \& Plank, T. 1992 Petrological systematics of mid-ocean ridge basalts: constraints on melt generation beneath ocean ridges. In Mantle flow and melt generation at mid-ocean ridges (ed. J. Phipps Morgan et al.), pp. 183-280. (Geophysical Monograph 71.) Washington, DC: AGU.

Longhi, J. 1992 Origin of green glass magmas by polybaric fractional fusion. Proc. Lunar Planet. Sci. 22, 343-353.

McKenzie, D. P. 1984 The generation and compaction of partial melts. J. Petrol. 25, 713-765.

McKenzie, D. P. \& Bickle, M. J. 1988 The volume and composition of melt generated by extension of the lithosphere. J. Petrol. 29, 625-679.

McKenzie, D. P. \& Bickle, M. J. 1990 A eutectic parameterization of mantle melting. J. Phys. Earth 38, 511-515.

McKenzie, D. P. \& O’Nions, R. K. 1991 Partial melt distributions from inversion of rare earth element concentrations. J. Petrol. 32, 1021-1091.

Miller, G. H., Stolper, E. M. \& Ahrens, T. H. 1991 The equation of state of a molten komatiite. 2. Applications to komatiite petrogenesis and the Hadean mantle. J. Geophys. Res. 96, 1184911864.

Niu, Y. \& Batiza, R. 1991 An empirical method for calculating melt compositions produced beneath mid-ocean ridges: application to axis and off-axis (seamounts) melting. J. Geophys. Res. 96, $21753-21777$.

Ramberg, H. 1972 Mantle diapirism and its tectonic and magmagenic consequences. Phys. Earth. Planet. Interiors 5, 45-60.

Rigden, S. M., Ahrens, T. J. \& Stolper, E. M. 1989 High-pressure equation of state of molten anorthite and diopside. J. Geophys. Res. 94, 9508-9522.

Phil. Trans. R. Soc. Lond. A (1997) 
Rumble, D. 1976 The adiabatic gradient and adiabatic compressibility. Carn. Inst. Wash. Yb. 75, 651-655.

Scott, D. R. \& Stevenson, D. J. 1989 A self-consistent model of melting, magma migration and buoyancy-driven circulation beneath mid-ocean ridges. J. Geophys. Res. 94, 2973-2988.

Solomatov, V. S. \& Stevenson, D. J. 1994 Can sharp seismic discontinuities be caused by nonequilibrium phase transformations? Earth Planet. Sci. Lett. 125, 267-279.

Sparks, D. W. \& Parmentier, E. M. 1991 Melt extraction from the mantle beneath spreading centers. Earth Planet. Sci. Lett. 105, 368-378.

Spiegelman, M. 1993 Flow in deformable porous media. 2. Numerical analysis - the relationship between shock waves and solitary waves. J. Fluid Mech. 247, 39-63.

Stebbins, J. F., Carmichael, I. S. E. \& Weill, D. J. 1983 The high-temperature liquid and glass heat contents and heats of fusion of diopside, albite, sanidine, and nepheline. Am. Mineral. 68, 717-730.

Takahashi, E. 1986 Melting of a dry peridotite KLB-1 up to 14 GPa: implications on the origin of peridotitic upper mantle. J. Geophys. Res. 91, 9367-9380.

Takahashi, E. \& Kushiro, I. 1983 Melting of a dry peridotite at high pressures and basalt magma genesis. Am. Mineral. 68, 859-879.

Turcotte, D. L. \& Ahern, J. L. 1978 A porous flow model for magma migration in the asthenosphere. J. Geophys. Res. 83, 767-772.

Verhoogen, J. 1965 Phase changes and convection in the Earth's mantle. Phil. Trans. R. Soc. Lond. A 258, 276-283.

\section{Discussion}

R. W. NeSBITT (Southampton Oceanography Centre, University of Southampton, $U K)$. In Professor Stolper's discussion dealing with the behaviour of melts under batch melting and fractional melting conditions he drew attention to the fact that in the case of the latter, melting would cease when the upwelling peridotite reached a phase transition (such as the spinel to plagioclase peridotite transition). Melting would then resume at a later stage once there had been a sufficient pressure drop. Presumably this cessation would result in a significant change in melt chemistry and the process may even be used to explain the $\mathrm{MgO}$ gap between komatiites which have 20-32 wt\% MgO and high magnesian basalts (commonly called komatiitic basalts) which range from $15 \% \mathrm{MgO}$ downwards?

E. M. Stolper. There would certainly be a compositional gap between melts produced before and after the cessation of melting at a sufficiently strong phase transition. However, it is unlikely that either the spinel-plagioclase or garnet-spinel peridotite transitions are responsible for the gap between komatiites and komatiitic basalts. The spinel-plagioclase peridotite transition would not play a role at the high temperatures and high degrees of melting of komatiite genesis, and the garnet-spinel peridotite transition would have too small an effect in common upper mantle compositions to produce a large gap in $\mathrm{MgO}$ content. On the other hand, if decompression melting were to begin in the transition zone, the phase change associated with the $410 \mathrm{~km}$ discontinuity might result in a significant gap between melts from the transition zone and the overlying upper mantle. Whether this could help to explain the origin of komatiites is difficult to say. 